NBER WORKING PAPER SERIES

\title{
DEREGULATION, CONSOLIDATION, AND EFFICIENCY: EVIDENCE FROM U.S. NUCLEAR POWER
}

\author{
Lucas W. Davis \\ Catherine Wolfram \\ Working Paper 17341 \\ http://www.nber.org/papers/w17341
NATIONAL BUREAU OF ECONOMIC RESEARCH
1050 Massachusetts Avenue
Cambridge, MA 02138

August 2011

We are thankful to Catie Hausman for outstanding research assistance. Comments from Matt Barmack, Severin Borenstein, Paul Joskow, Per Peterson, Scott Taylor and seminar participants at Colorado, UC Davis, the AERE Summer Conference, the NBER EASE Conference and the NBER Summer Institute substantially improved the paper. This work was funded by a grant from the California Energy Commission. The views expressed herein are those of the authors and do not necessarily reflect the views of the National Bureau of Economic Research.,

NBER working papers are circulated for discussion and comment purposes. They have not been peerreviewed or been subject to the review by the NBER Board of Directors that accompanies official NBER publications.

(C) 2011 by Lucas W. Davis and Catherine Wolfram. All rights reserved. Short sections of text, not to exceed two paragraphs, may be quoted without explicit permission provided that full credit, including (C) notice, is given to the source. 
Deregulation, Consolidation, and Efficiency: Evidence from U.S. Nuclear Power

Lucas W. Davis and Catherine Wolfram

NBER Working Paper No. 17341

August 2011

JEL No. D21,D40,L51,L94,Q48

\begin{abstract}
For the first four decades of its existence the U.S. nuclear power industry was run by regulated utilities, with most companies owning only one or two reactors. Beginning in the late 1990s electricity markets in many states were deregulated and almost half of the nation's 103 reactors were sold to independent power producers selling power in competitive wholesale markets. Deregulation has been accompanied by substantial market consolidation and today the three largest companies control more than one-third of all U.S. nuclear capacity. We find that deregulation and consolidation are associated with a 10 percent increase in operating efficiency, achieved primarily by reducing the frequency and duration of reactor outages. At average wholesale prices the value of this increased efficiency is approximately $\$ 2.5$ billion annually and implies an annual decrease of almost 40 million metric tons of carbon dioxide emissions.
\end{abstract}

\author{
Lucas W. Davis \\ Haas School of Business \\ University of California \\ Berkeley, CA 94720-1900 \\ and NBER \\ ldavis@haas.berkeley.edu \\ Catherine Wolfram \\ Haas School of Business \\ University of California, Berkeley \\ Berkeley, CA 94720-1900 \\ and NBER \\ wolfram@haas.berkeley.edu
}




\section{Introduction}

Market deregulation has been one of the dominant economic trends worldwide over the last 30 years. Economic theory implies that competition provides incentives for firms to increase efficiency, cut costs, and make prudent investments in capacity and technological innovation. A broad literature has developed in economics evaluating this transformation from both theoretical and empirical perspectives. Among the markets that have received the most attention are airlines, financial services, telecommunications, transportation and energy. ${ }^{1}$

Over this period many industries have also been characterized by large increases in the degree of market consolidation. Here economic models describe a basic tradeoff between economies of scale and the ability of larger firms to exercise market power. Again, government plays a central role, with antitrust policies determining the degree of concentration in a variety of different important markets. An extensive literature in industrial organization provides a guide for assessing the potential impact of consolidation on a number of market outcomes, including pricing, costs, investment and entry. Though firms confronting a potential merger review often argue that there will be cost efficiencies from consolidation, there is comparatively little evidence evaluating such claims. ${ }^{2}$

This paper examines an unprecedented period of deregulation and consolidation in the U.S. nuclear power industry. For four decades all nuclear power reactors in the United States were owned by regulated utilities. Few utilities owned more than one or two reactors and utilities received a rate of return on their capital investments that was largely disconnected from operating efficiency. Beginning in the late 1990s electricity markets in many states were deregulated and 48 of the nation's 103 nuclear power reactors were sold to independent power producers selling power in competitive wholesale markets. These divestitures have led to substantial market consolidation and today the three largest companies control more than one-third of all U.S. nuclear capacity.

\footnotetext{
1 See Joskow and Rose (1989), Winston (1993), Peltzman and Winston (2000), and Joskow (2005) for reviews of this literature.

2 Several empirical papers examine the effect of market structure on efficiency. See, for example, Olley and Pakes (1996), Borenstein, Bushnell and Wolak (2000), Focarelli and Panetta (2003) and Syverson (2004). Most of these papers focus on efficiencies gained from reallocations across firms.
} 
There are a number of reasons why the U.S. nuclear power industry is a particularly good candidate for a study of the relationship between deregulation, consolidation, and efficiency. First, electricity is a homogeneous good that is accurately and consistently measured across space and time. Second, nuclear reactors produce electricity at very low marginal cost so they are always used as "baseload" generation, meaning they are not turned off during periods of low demand. These two facts provide us with a substantial advantage over previous studies that have attempted to measure firm-level productivity as they allow us to use publicly available data to construct a highly reliable and consistent measure of operating efficiency that is not contaminated by differences in product quality across firms, unobserved demand, or local market price shocks. ${ }^{3}$ Third, during the relevant period there is very little entry or exit of nuclear reactors, mitigating concerns about selection that substantially complicate similar analyses. Fourth, deregulation and consolidation occurred rapidly and for only half of all reactors, lending credibility to the empirical analysis by facilitating comparisons both across reactors and over time.

Using a unique 40-year monthly panel of all nuclear reactors in the United States we find that deregulation and consolidation are associated with a 10 percent increase in operating efficiency, achieved primarily by reducing the frequency and duration of reactor outages. Efficiency gains were experienced broadly across reactors of different types, manufacturers, and vintages, with the largest increases in the spring and fall during the peak months for refueling. We also examine explicitly the role of consolidation, comparing efficiency gains across companies that operate different numbers of reactors. While we find evidence that consolidation led to improved operating efficiency, it explains little of the overall increase.

Our results imply a substantial increase in electricity production. In 2009 U.S. nuclear reactors produced 800 billion kilowatt hours of electricity, about $20 \%$ of total U.S. electricity generation. We estimate that the increase in electricity production due to deregulation and consolidation exceeds 40 billion kilowatt hours annually. At current average wholesale prices, the value of the increased electricity production is approximately $\$ 2.5$ billion annually. This increase is almost pure efficiency gain, achieved without building a single new plant or constructing a single additional mile of transmission capacity.

3 Adequately controlling for demand-side factors is a key challenge in the broader productivity literature. See Syverson (2011) for a recent survey. 
In addition, because the increased electricity production displaces mostly coal- and natural-gas- fired power, these gains in efficiency also have substantial implications for the environment, implying an annual decrease of 38 million metric tons of carbon dioxide emissions. Using a conservative estimate for the social cost of carbon dioxide ( $\$ 20$ per ton) this is an additional $\$ 760$ million in benefits annually. To put this into perspective, this is more carbon abatement than was achieved by all the U.S. wind and solar generation combined during the same period. Whereas there are explicit programs directed at promoting low-carbon energy in the case of wind and solar, this decrease in carbon emissions is noteworthy because deregulation is not usually envisioned as a means for achieving environmental goals. ${ }^{4}$

Finally, we perform a similar analysis for an available measure of reactor safety. Whereas economic theory provides clear predictions for operating efficiency, the effect of deregulation on safety is ambiguous and depends on whether safety is a complement or a substitute to operating efficiency (MIT 2003, Hausman 2011). We find that divestiture and consolidation are associated with a decrease in the number of emergency shutdowns, also known as "scrams." The point estimate is relatively noisy ( $p$-value .09), but is estimated with enough precision to reject increases larger than 5\%. Safety is inherently much more difficult to measure than operating efficiency and although we view these results as suggestive, scrams are a highly imperfect measure of safety and as more and richer data become available it will be important to revisit this important issue.

Our results are relevant to current policy discussions about the future of U.S. nuclear power. Concerns about climate change, energy security and volatile fossil-fuel prices have emboldened proponents of nuclear power, with some even forecasting a nuclear "renaissance." No new reactors have come online in the United States since the mid-1990s, but between 2007 and 2009 the Nuclear Regulatory Commission (NRC) received license applications for 26 proposed new nuclear reactors. ${ }^{5}$ Several recent studies (MIT 2003, MIT 2009, Joskow and Parsons 2009) compare the lifetime costs of nuclear to other generating

\footnotetext{
${ }^{4}$ Moreover, estimates from Borenstein (2008) and Joskow (2011) imply that to have obtained this same level of carbon abatement through wind or solar generation would cost more than $\$ 10$ billion annually. Borenstein (2008) calculates an implied carbon dioxide mitigation cost of $\$ 300-600 /$ ton for rooftop solar photovoltaics. Joskow (2011) calculates an implied carbon dioxide mitigation cost of $\$ 300 /$ ton for the Cape Wind offshore wind project.

5 See Table 9 in U.S. NRC. “Information Digest 2010-2011” NUREG-1350, Volume 22, published August 2010.
} 
alternatives and highlight the importance of nuclear operating efficiency in these calculations.

The format of the paper is as follows. Section 2 provides background information about the nuclear power industry and the broader electricity market. Sections 3 and 4 describe the data and empirical strategy. Section 5 includes the main results, presenting estimates of the effect of divestiture and consolidation on nuclear reactor efficiency for a variety of different specifications including a set of regressions aimed at addressing potential concerns about selection bias. Section 6 presents additional results aimed at better understanding the mechanisms driving the increase in efficiency, including ancillary evidence on investments in reactor capacity as well as on the frequency and duration of outages. Section 7 offers concluding comments.

\section{$2 \quad$ Background}

\subsection{Nuclear Power in the U.S. Electricity Industry}

Electricity is generated using several different technologies. In the United States the most important sources in terms of total electricity production are coal (45\%), natural gas (23\%), nuclear (20\%), hydro (7\%), and wind, solar, and other renewables (4\%). ${ }^{6}$ Nuclear reactors are expensive to build, but then produce power at lower marginal cost than most other generating technologies. Coal and natural gas plants produce power at higher marginal cost, but require smaller initial capital investments. ${ }^{7}$ The other key difference between nuclear and other forms of electricity generation is the ease with which output can be adjusted to meet variable electricity demand. Nuclear power reactors typically take several days to ramp up or ramp down, and thus are usually shut down only for refueling, maintenance or in an emergency. At the other end of the spectrum are natural gas peaking plants which can be turned on and off almost instantly and with very low startup cost.

These features imply that nuclear reactors are typically used to provide baseload power, 24 hours a day. This explains why in the United States nuclear power accounts for

\footnotetext{
6 These shares are from 2009 according to U.S. Department of Energy, Energy Information Administration, Annual Energy Review 2009, released August 2010, Table 8.2a "Electricity Net Generation."

7 MIT (2009) reports fuel costs (per MWh) of $\$ 23$ and $\$ 48$ for coal- and natural gas-fired power plants but only $\$ 7$ for nuclear power, based on fuel prices of $\$ 2.60, \$ 7.00$, and $\$ 0.67$ per million BTU and average heat rates of $8,870,6,800$, and 10,400 BTU per kilowatt hour, respectively.
} 
only $10 \%$ of capacity but produces $20 \%$ of total electricity. ${ }^{8}$ As electricity demand peaks during the day, other forms of generation come online to meet this demand. In the United States, the fraction of electricity generated by nuclear reactors is small enough that there is enough demand to keep nuclear reactors operating even during the lowest consumption periods in the middle of the night.

Because nuclear power is baseload, the operating behavior of plants is largely unaffected by changes in electricity demand. Average fuel costs for nuclear plants $(\$ 7$ per MWh) are low compared to wholesale prices, so nuclear operators strive to minimize planned and unplanned outages. ${ }^{9}$ From an empirical perspective this is extremely advantageous because it makes it easier to focus on structural changes on the supply side of the market, and essentially eliminates concerns about these changes being correlated with observed or unobserved changes in demand. ${ }^{10}$ Similarly, the entry or exit of other generating units does not typically have any effect on how nuclear plants are operated because in all cases the reactors continue to provide baseload generation. In contrast, coal and natural gas plants produce power at higher marginal cost, so these facilities are turned on and off in response to demand fluctuations. Consequently, empirical studies of fossil-fuel generation must include adequate controls or risk confounding changes in demand with changes in efficiency. ${ }^{11}$

Nuclear plants are very large so even small improvements in operating efficiency

\footnotetext{
8 U.S. Department of Energy, Energy Information Administration, Annual Energy Review 2009, released August 2010, Tables 8.11a “Electric Net Summer Capacity" and 8.2a “Electricity Net Generation." In 2009, nuclear power accounted for $9.8 \%$ of net summer capacity and $20.2 \%$ of total net generation.

9 This includes ore purchase, yellow cake conversion, and enrichment (MIT 2009). Fuel costs are by far the largest component of variable operating costs for nuclear plants. Variable operations and maintenance costs (excluding fuel) are $\$ 0.51$ per MWh according to U.S. Department of Energy, Energy Information Administration, Assumptions to the Annual Energy Outlook 2010, Table 8.2. "Cost and Performance Characteristics of New Electricity Generating Technologies" so fuel costs are over $90 \%$ of the marginal cost of nuclear power.

10 Adequately controlling for demand-side factors is a key challenge in the broader productivity literature. For example, in his recent survey, Syverson (2011) makes the point that, "[b]ecause producer-specific prices are unobserved in most business-level microdata, output is typically measured by revenue divided by an industrylevel deflator. This means that within-industry price differences are embodied in output and productivity measures. If prices reflect in part idiosyncratic demand shifts or market power variation across producers-a distinct likelihood in many industries-then high "productivity" businesses may not be particularly technologically efficient. Much of the literature described above therefore documents the joint influence of productivity and demand factors that show up in within-industry price variation" (p.357).

11 There may be a second-order effect of demand- and supply-side factors on nuclear power operations since higher prices will make it even more profitable to keep the nuclear reactor online. Owners may invest more in ensuring that the reactor continues to operate if they face high prices. Below we present evidence suggesting that, at least in the very short-run, nuclear outages are not timed to match short-run fluctuations in market prices. Also, the gains from divestitures do not vary by geographic region, even though average wholesale prices do.
} 
imply substantial amounts of electricity. Consider, for example, a typical two-reactor $2000 \mathrm{MW}$ nuclear plant. At typical wholesale electricity prices ( $\$ 60$ per $\mathrm{MWh}$ ), a plant that operates $80 \%$ of the year produces power worth approximately $\$ 840$ million dollars annually. An increase from $80 \%$ to $85 \%$ increases revenues by $\$ 52$ million dollars annually, $\$ 120,000$ for each additional hour that the plant is operating. Given the low marginal cost of nuclear generation, this is essentially all profit.

\subsection{The Regulation and Deregulation of the U.S. Electricity Industry}

Traditionally electricity was regarded as a natural monopoly. In the standard regulatory model still used in many states today, investor- and, in some cases, municipally and federally-owned utilities receive exclusive rights to provide electricity within given geographic areas and are allowed to charge rates set by cost-of-service regulation. These vertically-integrated utilities typically perform all the activities required to supply electricity to residential, commercial, and industrial customers including generating electricity, operating the transmission and distribution networks, and providing retail services such as billing and customer service.

Under cost-of-service regulation, rates are set to allow utilities to recover their recurring operating expenses as well as earn a rate of return on all capital investments in generating equipment as long as that equipment is "used and useful" (F.P.C. vs. Hope Natural Gas Co., 320 U.S. 591, 1944). This creates little incentive for companies to operate their plants efficiently, including their nuclear reactors, because they receive this compensation regardless of the level of performance. Poor operating efficiency at a utility's nuclear plant means that it must operate other higher-cost generating units more. Rates are then adjusted, however, to reflect these higher operating costs making the regulated utility essentially indifferent between the generating facilities in its portfolio. While in theory a regulator could disallow costs for a utility with poor nuclear operating efficiency, this rarely happens in practice. Nuclear power production is highly idiosyncratic and all plants occasionally have problems that lead to suboptimal operating efficiency. Knowing which problems are due to bad luck and which are due to poor management is a challenging, 
unwelcome job for a utility commission, who customarily leave day-to-day operating decisions to the utility company management.12

Recognizing that traditional cost-of-service regulation provides little incentive for cost-minimization, several states implemented some form of incentive regulation in the 1980s and early 1990s. ${ }^{13}$ These policies varied from state to state but in all cases were designed to create incentives for firms to increase output and cut costs. Some states implemented incentive programs tied to the operation of particular plants, including nuclear plants.

In perhaps the best-known example, the California Public Utility Commission agreed in 1988 to allow Pacific Gas and Electric Company (PG\&E) to collect a fixed price for every kilowatt hour of electricity produced by the Diablo Canyon nuclear plant. As the outcome of a lawsuit settlement, the price was fixed for over ten years and was not to be adjusted to reflect cost savings or capacity factor improvements at the plant. This created an incentive for PG\&E to increase plant efficiency, and, indeed, the plant's capacity factor increased substantially after the plan was implemented. In a classic case of the ratchet effect, state regulators adjusted the price downward six years into the scheme, in the face of PG\&E's huge profits at the previously negotiated price.

In other states, incentive regulation was less precisely linked to particular plants, but, for instance, allowed the utility to earn a higher rate of return if it maintained a prespecified average availability across all of its plants. At the end of 1990, sixty nuclear reactors, operating in sixteen states were subject to some form of incentive regulation (Verma, Mitnick and Marcus, 1999). Empirical work at the time found that the incentive programs had mixed success at raising average capacity factors at nuclear plants.

Another mechanism that potentially creates incentives for operating efficiency is regulatory lag. Particularly during periods of low inflation for input costs, several years can elapse between rate cases. (It is very rare to have a rate case initiated by a party other than the utility.) Between rate cases, utilities are essentially facing a price-cap, which gives them incentives to minimize costs in the short run (Joskow, 1973). In the mid to late 1990s, for

\footnotetext{
12 There were a number of cases in which regulators disallowed construction costs for nuclear plants (Lyon and Mayo, 2005).

13 Knittel (2002) studies the impact of incentive regulation in the U.S. electricity industry on fossil-fuel-powered generating plants.
} 
example, there were very few rate cases, partly as state regulatory commissions began hearings on deregulation.

In part as a response to the limitations of cost-of-service regulation, several states began to deregulate their electricity markets beginning in the late 1990s. See White (1996) and Joskow (1997) for overviews of the deregulation process. In most states, the deregulation process separated electricity generation, which most economists believe is potentially competitive, from transmission and distribution. Wholesale electricity markets were established in several different regions, and these markets facilitated the growth of independent (nonutility) power producers. Regulators also strongly encouraged utilities to sell all or part of their existing electric generating portfolios.

Divestitures fulfilled several goals. First, they helped jumpstart the nascent nonutility sector. Many regulators were concerned that vertically integrated companies could distort the wholesale markets, as they would serve as both buyers and sellers into these markets, as well as owners of the transmission grid to which any nonutility supplier would need access. Vertical separation alleviated these concerns. Also, the proceeds from the divestitures reimbursed the utilities for any unrecovered costs, thereby avoiding the "stranded cost" problem. Divestitures peaked between 1998 and 2002, during which time over 300 electric generating plants were sold and reclassified as independent power producers. Divestitures continued at a slower pace 2003-2010, and by the end of the decade $35 \%$ of U.S. electricity capacity was controlled by independent power producers. ${ }^{14}$

The timing of the nuclear plant divestitures followed the broader industry trend. By as late as the end of 1998, all U.S. nuclear reactors were still owned by traditional electric utilities. Then between 1999 and 2002, a total of 36 reactors were divested and reclassified as independent power producers. An additional 12 reactors were divested between 2004 and 2007. See Appendix Table 1 for a complete list of divestitures.

A number of empirical papers have evaluated the effects of U.S. electricity restructuring, including its impact on the efficiency of the wholesale power markets (Borenstein, Bushnell and Wolak, 2000; Bushnell, Mansur and Saravia, 2008; and Hortacsu and Puller, 2008), consumer responses to retail competition (Hortacsu, Madanizadeh and Puller, 2011) and improvements in inter-regional cost-minimization across power plants

14 Table 1.1 in U.S. Department of Energy, Energy Information Administration, Electric Power Annual, DOE/EIA0226, revised April 2011. 
(Mansur and White, 2010). Several closely related studies examine the effects of electricity restructuring on plant operations, although much of the existing work has focused on electricity production from fossil-fuel plants. See, e.g., Wolfram (2004), Bushnell and Wolfram (2005), Fabrizio, Rose, and Wolfram (2007), and Craig and Savage (2011).

Nuclear power has received less attention. Zhang (2007) examines the impact of electricity restructuring on nuclear plant operating efficiency during the period 1992-1998, prior to the beginning of plant divestitures. Our analysis adds $10+$ years of additional data from the key period after deregulation, as well as 20+ years of data from before 1992 . Both Zhang (2007) and Fabrizio, Rose, and Wolfram (2007), in their study of fossil-fuel plants, restrict their analyses to the period before divestitures as both studies use data on plant inputs and output from the Federal Energy Regulatory Commission's (FERC) Form 1, which is for electric utilities but and not for independent power producers. Our study uses publicly available data sources that are unique to nuclear reactors. Because the safety of nuclear reactor operations are subject to heavy regulatory scrutiny, all nuclear plants including independent power producers are required to report monthly reactor status to the Department of Energy as well as daily reactor status to the NRC. This information is available for all plants and years and is available for each individual reactor inside multireactor plants, unlike the information available from FERC. ${ }^{15}$

\section{$2.3 \quad$ Market Power}

Both academics and regulators have devoted considerable attention to identifying and mitigating market power in deregulated wholesale markets (see, e.g., Wolfram 1999, Borenstein, Bushnell, and Wolak 2002, and Joskow and Kahn, 2002). To prevent the exercise of market power, regulators have established bid caps, set up market monitoring commissions, and blocked an attempted merger. ${ }^{16}$

Whatever market power was present during the time period we study, it is unlikely to have influenced nuclear plant operations. Operators of nuclear reactors typically will not

15 This distinction is important because in the United States it is common for reactors in multi-reactor plants to be very different. For example, the Millstone nuclear power plant in Connecticut has two reactors that were completed nine years apart (1975 and 1986), of different design capacities (870 and 1156 megawatts), and made by different manufacturers (Combustion Engineering and Westinghouse).

16 For example, a 2004 proposed merger between Exelon and Public Service Enterprise Group of New Jersey was eventually called off, in part because the companies balked at the regulators' proposed market-power mitigation measures. 
attempt to exercise market power unilaterally. Previous work has examined the scope for electricity generators to exercise market power in wholesale electricity markets by submitting bids above marginal cost (see, e.g., Borenstein, Bushnell, and Wolak 2002). However, because the marginal cost of nuclear power is low relative to typical market clearing prices, the operator of a nuclear plant would need to submit a bid substantially above its marginal cost in order to influence prices. And bidding above marginal cost is risky because if demand ends up being different than expected, or if other generators bid differently than expected, the nuclear plant can find itself out of the queue and not producing power. This is particularly costly for a nuclear plant because it means that it does not receive the substantial inframarginal rent that it would otherwise receive. Moreover, because of the long ramping times for nuclear reactors, it may be several days before the plant can operate again at full power.

The real scope for market power comes, instead, from companies that operate a portfolio of nuclear and non-nuclear generating plants. A diversified company may find it profitable to withhold capacity from plants whose marginal costs are closer to the expected market clearing price. Indeed, the incentive to exercise market power with these units is increasing in the amount of inframarginal capacity that the company has (nuclear or other low marginal cost technologies). It is clear that the market consolidation that occurred in the U.S. nuclear industry beginning during the late 1990s has increased the scope for market power, and in future work it would be interesting to examine this behavior explicitly. It is worth emphasizing, however, that regardless of whether or not a company withholds output from its marginal plants, it still will make sense for the company to continue to operate its nuclear power plants as much as possible.

\section{$3 \quad$ Data Description}

This study is conducted using the most comprehensive dataset ever compiled on the operating efficiency of U.S. nuclear power reactors. Our primary dataset describes forty years of monthly operating efficiency for the universe of U.S. nuclear power reactors. This long panel is important because it allows us to use a variety of different approaches for addressing possible concerns about selection and pre-existing trends. We also put considerable effort into constructing detailed histories of the companies that own and 
operate nuclear reactors - information that we use to construct our measures of divestiture and consolidation. The 40-year monthly panel was constructed using data from the U.S. Department of Energy's Power Plant Report (EIA-923). ${ }^{17}$ The Power Plant Report is a monthly survey of operators of nuclear reactors and other large electric generating facilities that includes total electricity generation and other information. ${ }^{18}$ The compiled dataset provides a complete record of monthly generation for all reactors from 1970 to 2009. Of the 103 reactors used in our analysis, only two began commercial operation prior to 1970 so the dataset includes the entire operating history for all but two reactors. ${ }^{19}$ Reactor outages are recorded as zeros. There are no missing observations.

During the relevant period there is very little entry or exit of nuclear reactors. This simplifies the analysis considerably because it mitigates concerns about selection bias that have been an important issue in analyses of deregulation in other markets (e.g. Olley and Pakes 1996). We include in the main analysis all U.S. nuclear power reactors that were operating as of January 1, 2000. This excludes a small number of reactors that were closed during the 1990s, including Millstone 1 and San Onofre 1. No nuclear reactors have been closed in the United States since 1998. As of 2011 there are 104 operating nuclear reactors in the United States. We have 103 in our panel because we have excluded Browns Ferry 1 which was closed for more than two decades between 1985 and 2007.

The most commonly reported measure of nuclear reactor operating efficiency is the capacity factor,

$\frac{\text { net generation }(\text { in } M W h)}{\text { maximum potential generation }(\text { in } M W) * \text { number of hours }} * 100$.

\footnotetext{
17 Previous versions of the EIA-923 were the EIA-906 and EIA-759.

18 Reactor operators report monthly net electricity generation in megawatt hours (MWh). With electricity generation there is a distinction between gross generation and net generation, where net generation accounts for the electricity consumed by the plant itself and therefore can be negative during shutdowns. Power plants are supposed to report net generation rather than gross generation, but the presence of many exact zeros, particularly during the 1970 s and 1980s suggests that at least some plants during some years were reporting gross generation instead. Fortunately in practice the difference is negligible for nuclear power plants because on-site electricity consumption averages less than $1 \%$ of total electric generation.

19 During 1970-1985 and 2001-2002, generation in the Power Plant Report is reported at the plant level but not reported separately for individual reactors within multi-reactor plants. Of the 65 plants in our sample, 29 have one reactor, 33 have two reactors and 2 plants have three reactors (Oconee and Palo Verde). During these years for multi-reactor plants we impute reactor-level measures of generation by assigning plant-level generation to each reactor proportionately to each reactor's capacity. This imputation is unlikely to bias our results because divestitures tend to occur at the same time for all reactors in multi-reactor plants. The one exception is Indian Point where prior to 2001 the plant's two active reactors had different owners. It turns out, however, that because of this ownership structure the Power Plant Report includes reactor-level generation for Indian Point for all years, making no imputation necessary. Later in the paper we re-estimate the model at the plant level and, as expected, the results are very similar.
} 
Capacity factor is calculated as the ratio of actually generated power and maximum potential generation. Usually reported in percent as it is here, the capacity factor is a convenient summary measure of efficiency that is easily interpretable and facilitates comparisons of efficiency across reactors of different sizes.

For our baseline estimates we use a closely related measure,

$$
\frac{\text { net generation }(\text { in } M W h)}{\text { reactor design capacity }(\text { in } M W) * \text { number of hours }} * 100 \text {. }
$$

When reactor design capacity is equal to maximum potential generation these two measures are identical. The important difference between (1) and (2) is that reactor design capacity does not change over time whereas maximum potential generation may change over the lifetime of a reactor. Consequently, the latter measure reflects both the intensity with which the reactor is used and changes over time in maximum potential generation. Whereas capacity factor never exceeds 100, our measure can exceed 100 for a reactor that on average during a period operates at a level of generation above the reactor design capacity. Later in the paper we examine these two components separately, but for the baseline estimates it is valuable to have a single measure. ${ }^{20}$ We use the reactor design capacities reported in U.S. Department of Energy, Energy Information Administration, Nuclear Power Generation and Fuel Cycle Report 1997, “Appendix C: Nuclear Units Ordered in the United States, 1953-1996."

The Power Plant Report also contains information about reactor operators including whether the reactor operator is a utility or a nonutility. We use this information to construct an indicator variable for reactors that have been divested. We identify divestitures in the Power Plant Report as the first month in which a reactor changes its status from utility to nonutility. ${ }^{21}$ These same data were also used to describe industry consolidation. For each

\footnotetext{
${ }^{20}$ For our baseline estimates we might have alternatively used net generation itself (without this scaling) or net generation in logs. We prefer the scaled measure to net generation without scaling because U.S. reactors vary widely in design capacity. Net generation in logs would help address this issue, but is not well suited to our application because we have a large number of zeros and negative numbers for net generation.

21 See Appendix Table 1 for the complete list of divestitures. Because this variable is central for our analysis we put considerable effort into cross-checking divestiture dates against alternative sources. Our primary alternative source of divestiture dates is the U.S. Department of Energy, Energy Information Administration, Electric Power Monthly, which in March issues between 2000 and 2003 includes a table "Electric Utility Plants That Have Been Sold and Reclassified" listing generating facilities that have been reclassified as non-utilities. For the years in which Electric Power Monthly is not available we cross-checked the divestiture dates against SEC filings from the companies involved in the transaction. In the vast majority of cases the different sources report the same divestiture date. For a small number of cases in which there were minor discrepancies in divestiture dates between the different sources we rely on SEC filings. Also in some cases the Power Plant Report identifies the
} 
reactor and month observation we calculate the number of other reactors operated by that reactor's operator. ${ }^{22}$ In cases where companies are subsidiaries of other companies we treat this as the same company. Where this is unclear we used SEC filings to determine the ownership structure. ${ }^{23}$ Much, but not all, of the variation in consolidation is driven by divestitures so our careful treatment of the divestiture dates and operator changes helps ensure the accuracy of this measure.

We also use data from the U.S. NRC's Power Reactor Status Reports. These data are available for a shorter time period (1999-2009), but are available daily compared to monthly for the Power Plant Report. With higher frequency data, we can evaluate reactor outages with considerably more detail. Reactors are required to submit daily reports to the NRC describing capacity factor in percent. Reactors reporting less than $100 \%$ provide a brief explanation and reactors that are completely shutdown report whether the outages was due to a manual shutdown (e.g. refueling or maintenance) or an automatic shutdown, also known as a "scram." The daily data are a complete panel with no missing observations during this 11 year period; a total of 4,017 total days.

We augment the operating data from the Power Plant Report and Power Reactor Status Reports with time-invariant reactor characteristics including reactor type, reactor manufacturer, and the date that each reactor began commercial operation from the $N R C$ Information Digest 2010-2011 (NUREG-1350, Volume 22), published August 2010, Appendix A “U.S. Commercial Power Reactors." Table 1 provides descriptive statistics. Panel A reports reactor characteristics. Reactor openings peaked during the 1970s and 1980s and most reactors had been operating for more than 10 years when divestitures began in 1999. The descriptive statistics show that U.S. reactors consist of two different reactor types produced by four different reactor manufacturers. ${ }^{24}$ Later in the paper we evaluate whether operating

year but not the month of divestiture and we have used the alternative sources to determine the exact month.

22 The Power Plant Report elicits information about reactor "operators" rather than "owners." For most reactors there is no distinction between the two. However, there are few reactors with multiple owners. In these cases typically the reactor is operated by the majority owner. There are also a small number of cases in which reactor owners signed operating contracts with outside companies.

23 One complication is that AmerGen, at the time of some of the divestitures was $50 \%$ owned by Exelon and $50 \%$ owned by British Energy. In the baseline specification we treat these reactors as being wholly owned by Exelon. Results are essentially identical when we alternatively calculate consolidation for these reactor-month observations by multiplying by .50 the number of reactors owned by each of the co-owners. The simple correlation between the two consolidation measures exceeds 99.

${ }^{24}$ In a nuclear reactor enriched uranium creates a chain reaction that creates heat that is used to produce electricity. Heat is produced either in the form of super-heated water in a pressurized water reactor or as steam 
efficiency differs systematically across these different designs.

Panel B in Table 1 describes operating efficiency and outages. Mean net generation as a percent of design capacity increases substantially over our sample period from $61 \%$ during the 1970 s to $92 \%$ during the 2000 s. The daily reactor status data from the NRC reveals that reactors tend to operate either at full capacity or not at all. In our sample, $77 \%$ of all daily observations are $100 \%$ capacity factor and $9 \%$ are $0 \%$ capacity factor. It is relatively common for reactors to operate between $90 \%$ and $99 \%$ but capacity factors between $1 \%$ and $89 \%$ are less common and usually indicate a reactor that is ramping up or ramping down, rather than a reactor that is permanently operating at an intermediate power level. For $45 \%$ of all observations between $1 \%$ and $89 \%$ we find that there is a reactor shutdown within 7 days, compared to $23 \%$ for reactors operating $90-99 \%$, and only $5 \%$ for reactors operating at $100 \%$.

Finally, the table describes reactor outages over the period 1999-2009. By far the most common explanation for reactor outages is refueling. Here we have defined refueling as any outage in which refueling was occurring, regardless of whether or not other forms of maintenance were occurring at the same time. A smaller fraction of shutdowns are for maintenance not related to refueling. Finally, about 2\% of shutdown-days were due to an automatic shutdown triggered by one of the reactor's safety systems. Also known as "scrams," this is when an operating nuclear reactor is shut down suddenly by rapid insertion of control rods, typically as a result of equipment or operator error. Whereas planned outages begin with a gradual decrease in power levels over several days, scrams shut down a reactor rapidly, putting great stress on plant equipment. There are a total of 831 scrams in our data, or 0.73 scrams per reactor year.

\section{$4 \quad$ Empirical Strategy}

\subsection{Graphical Analysis}

Figure 1 plots net generation as a percent of design capacity by year for reactors that were divested compared to all other reactors. The figure also plots on a different scale the number of operating reactors by year. Early in the sample there were few operating

in the case of a boiling water reactor. In our sample General Electric produced only boiling water reactors and the other three manufacturers produced only pressurized water reactors. 
reactors but by the 1990s all of the reactors in the sample are online. Net generation increases steadily throughout the forty-year period, from near $50 \%$ of reactor capacity to above 90\%. Worldwide, nuclear operating efficiency has followed a similar upward trajectory through the 1980s and 1990s. ${ }^{25}$ This industry-wide increase is usually attributed primarily to learning-by-doing (Joskow and Rozanski, 1979, Lester and McCabe 1993). "For a complicated piece of equipment like a nuclear power plant this type of learning includes the identification and correction of particular technical 'bugs' as well as increasing the ability of workers to use and maintain the equipment more effectively" (Joskow and Rozanski, 1979). Every piece of equipment in a nuclear reactor has now been studied for decades and inventive engineers have continued to find technical refinements, improvements, and adaptations that increase reliability.

For most of the sample the mean efficiency for divested reactors tracks reasonably closely the mean efficiency for all other reactors. During the 1980s and 1990s the mean efficiency for divested reactors tends to be somewhat lower than the mean efficiency for all other reactors. Then beginning in the late 1990s, the mean efficiency for divested reactors increases sharply and continues to increase during the 2000s. For every year between 2003 and 2009 the mean efficiency for divested reactors is higher than the mean efficiency for all other reactors. This period of increased mean efficiency corresponds with the years after which most divestitures had occurred. Although it is impossible to make definitive statements based on this time series, the pattern is consistent with a causal relationship between deregulation and operating efficiency with a group of reactors that were perennial underachievers converted almost immediately into a group of reactors that consistently outperform the rest of the industry. In the following subsections we turn to a regression framework that allows us to examine the relationship between divestiture, consolidation, and efficiency while controlling for a number of potentially important confounding factors.

It is also worth highlighting the pronounced dip in efficiency during the late 1990s among reactors that were subsequently divested. We have examined this period carefully and this dip in efficiency can be explained by several extended outages. During 1996, 1997, and 1998, ten reactors experience 12+ month outages - seven of which were reactors that were subsequently divested.26 In Section 5.4 we discuss potential concerns about selection

\footnotetext{
25 World Nuclear Association, “Optimized Capacity: Global Trends and Issues," undated.

26 In 1995 President Bill Clinton appointed Shirley Jackson to serve as the chair of the NRC. As part of a new
} 
bias and show that the results are similar in alternative specifications that exclude these long outages. One might have been concerned, in particular, that operators could have overhauled these reactors during the outages, potentially leading to improved long-run operating efficiency even in the absence of divestiture. We show in Section 5.4, however, that the results are similar excluding reactors that experienced long outages in 1996-1998. Although it is reassuring that our estimates are similar in these alternative specifications, for the main results it is important to use all observations including these periods of unusually poor operating efficiency. Divestiture makes plant operators acutely aware of the financial cost of outages. Extended outages, in particular, are disastrous for independent power producers, so they have incentive to go to great lengths to reduce their probability.

Finally, the figure also raises the possibility of learning spillovers from divested to non-divested reactors. It seems at least plausible that part of the potential gains from deregulation and consolidation would come in the form of learning about best practices, knowledge that at least in theory might quickly spread to regulated utilities. To the extent that these spillovers are important, our estimates of the effect of deregulation and consolidation would be biased downward. It is interesting to note, however, that while operating efficiency steadily increased during the 2000s among divested reactors, it was essentially flat at all other reactors. The companies such as Exelon that have made a business out of buying nuclear reactors claim that their operating success is difficult to duplicate, and this lack of recent improvement among non-divested reactors may provide some empirical support for that argument. ${ }^{27}$

\subsection{Covariate Balance}

The regression analysis described in the following sections is based on comparisons between divested and non-divested reactors, with the operating efficiency of non-divested reactors providing a counterfactual for what would have occurred at the divested reactors

reactor oversight program developed by Jackson, NRC inspectors identified dozens of problems at several different reactors culminating in the long outages observed during this period. Public concern about nuclear safety peaked following a March 1996 Time Magazine cover story, "Nuclear Warriors," March 4, 1996 by Eric Pooley and subsequent Senate investigation (see U.S. General Accounting Office, "Nuclear Regulation: Preventing Problem Plants Requires More Effective NRC Action,” GA0/RCED-97-145, May 1997).

27 In testimony before the New Jersey Board of Public Utilities in 2005, Exelon argued that, "[a] person does not become a great baseball player simply by reading best hitting and fielding practices, people do not become great business leaders simply by reading a book on best practices, and you certainly cannot run nuclear power plants just by reading procedures." 
during the 2000s had they not been divested. Whether or not this counterfactual is reasonable depends on whether the groups are ex ante similar, in terms of both observable and unobservable characteristics. Formal tests of unobserved characteristics are impossible but studies have argued that research designs that balance observable characteristics suffer less from omitted variables bias (Altonji, Elder, and Tamer 2005). In addition, when observable characteristics are similar between groups the exact functional form for the estimating equation becomes less important.

Table 2 compares all divested reactors with all other reactors. Many of the characteristics are similar in the two groups. Mean reactor capacity and mean reactor age, for example, are very similar. The table also reports $p$-values from tests that the means are equal. For none of the first four characteristics is the difference in means statistically significant. The table also describes reactor type and reactor manufacturer. The percentages differ between the two groups, but both groups include reactors of both types and from all four manufacturers. The most striking difference between the two groups is their geographic location. The divested reactors are primarily in the Northeast and Midwest, whereas two-thirds of the non-divested reactors are in the South. These differences reflect the geographic pattern of where electricity deregulation occurred in the United States.

Given the underlying differences between the two groups, we will be careful to control for reactor characteristics in the analysis that follows. The core of our strategy, detailed in the following subsection, is to emphasize within-reactor changes in efficiency over time, which allows us to control for time-invariant observable and unobservable reactor characteristics. Then in Section 5.4 we assess empirically whether selection bias or differential trends by reactor type could be influencing our estimates. We report results, for example, from alternative specifications which restrict the analysis to Census regions for which there is common support and which reweight the sample using propensity scores. The results from these robustness tests tend to be very similar to our baseline results, leading us to believe that, despite the underlying differences, the non-divested reactors provide a reasonably accurate counterfactual for how operating efficiency would have evolved in divested reactors in the absence of deregulation. 


\subsection{Estimating Equation}

This section describes the estimating equation used for our baseline estimates of the effect of divestiture on reactor operating efficiency. The approach is described by the following regression equation,

$$
Y_{\mathrm{it}}=\beta_{0}+\beta_{1} 1[\text { Divested }]_{\mathrm{it}}+\beta_{2} X_{i t}+\delta_{\mathrm{i}}+\omega_{\mathrm{t}}+\varepsilon_{\mathrm{it}}
$$

Here $i$ indexes reactors and $t$ indexes months, and in the baseline specification we include all reactor-month observations from the period 1970-2009, over 36,000 total observations. The dependent variable $Y_{\text {it }}$ is net generation as a percent of design capacity. Because the dependent variable is measured in percent all coefficient estimates should be interpreted as percentage points. The covariate of interest is $1[\text { Divested }]_{i t}$, an indicator variable for reactors that have been sold and reclassified as non-utilities. The coefficient of interest $\beta_{1}$ is the effect of divestiture on efficiency in percentage points. A positive coefficient provides evidence that, everything else equal, divested reactors have better operating efficiency than they would have achieved absent the divestiture.

We report results from specifications that include a range of different control variables. In the full specification we control for a cubic in reactor age $\left(X_{i t}\right)^{28}$, reactor fixed effects $\left(\delta_{i}\right)$, and month-of-sample fixed effects $\left(\omega_{t}\right)$. The reactor fixed effects play an important role in the regression, controlling for observed and unobserved physical characteristics such as size, reactor type, reactor manufacturer, cooling technology and other factors. The month-of-sample fixed effects are also important, particularly given the pronounced upward trend in efficiency throughout almost the entire sample period observed in Figure 1. Finally, the error term $\varepsilon_{\text {it }}$ captures unobserved differences in efficiency across reactor-months. ${ }^{29}$ In all results we cluster standard errors at the plant level allowing for arbitrary correlation over time and across reactors in multi-reactor plants.

\footnotetext{
${ }^{28}$ Joskow and Rozanski (1979) discuss two mechanisms by which reactor efficiency would tend to increase with age. First, there may be problems with the reactor as initially constructed (e.g. improperly installed equipment) that must be corrected. Second, there may be reactor-specific learning-by-doing by which operations and maintenance personnel become progressively more effective as they understand the idiosyncrasies of a particular reactor.

29 Our least-squares estimates describe the conditional mean of $Y_{\text {it }}$ for a set of explanatory variables. An alternative would have been to estimate a stochastic frontier production function describing the maximum amount of output obtainable from a given input bundle (see Aigner and Chu, 1968 and Aigner, Lovell and Schmidt, 1977). The disadvantage of this approach is that it requires one to make parametric assumptions about the error term. To examine the robustness of our results, in alternative results not reported we estimated
} 
Unbiased estimation of $\beta_{1}$ using least-squares requires that the error term $\left(\varepsilon_{\mathrm{it}}\right)$ is uncorrelated with $1[\text { Divested }]_{i t}$ conditional on the available covariates. Our preferred specification includes reactor fixed effects so underlying time-invariant differences between divested and non-divested reactors would not bias the results. However, the orthogonality condition could be violated if divestitures are correlated with trends in reactor efficiency. For example, if the reactors being divested are systematically those with more positive trends in efficiency this would bias upwards the estimates of $\beta_{1}$. We return to this issue in Section 5.4 and discuss several institutional details which provide reassurance that the divested reactors were not selected based on trends in operating efficiency or on the likelihood that particular reactors could be improved after market restructuring.

\subsection{Interpreting our Estimating Equation}

Several existing studies estimate production functions or cost functions with data from power plants. See, for example, Christensen and Greene (1976), Kleit and Terrell (2001) and Knittel (2002). ${ }^{30}$ Papers that specify a production function estimate the relationship between output, usually measured as annual kilowatt-hours produced, and inputs, usually including capital, labor, fuel, and, occasionally, materials. Papers that specify cost functions estimate the relationship between costs, input prices and output. With both approaches, studies typically use cross-sectional data on fossil-fuel plants, and impose a functional form on the production or cost function, such as Cobb-Douglas or translog. ${ }^{31}$

Although equation (3) is not a production function, we interpret the coefficient on $1[\text { Divested }]_{\text {it }}$, the variable of interest, as a measure of efficiency gains. Our dependent variable, net generation scaled by design capacity, is a measure of output much like what has been used in previous studies that estimate production functions. Where our estimation equation differs from previous work is that we do not explicitly include inputs. By far the

equation (3) using a stochastic frontier model with a composite error term composed of an inefficiency term assumed to be half-normal bounded above by zero and a normally-distributed idiosyncratic term. With this alternative model the estimated coefficient for $1[\text { Divested }]_{\text {it }}$ is similar but somewhat smaller than the baseline estimates presented later in the paper.

30 In related work, Bushnell and Wolfram (2005) and Fabrizio, Rose and Wolfram (2007) estimate factordemand equations, derived from a production function.

31 Fabrizio, Rose and Wolfram (2007) describe how certain functional form assumptions may not be appropriate for power plants and specify a production function which is Leontief in fuel inputs plus capital, labor, and materials. They derive factor demand equations for labor, materials and fuel, and hold capital fixed with plant fixed effects. 
most important input for nuclear power production is the capital embodied in the plant itself. Capital costs represent about $80 \%$ of the total cost of nuclear power, compared to, for example, only $15 \%$ for natural gas generation (Joskow and Parsons, 2009). Our preferred specifications include reactor fixed effects, which control for time-invariant differences in capital inputs across reactors. Also, month-of-sample fixed effects control for industry-wide changes in nuclear production (e.g., due to increased automation, or changes due to NRC regulations). Thus while we do not explicitly model reactor output as a function of inputs, these fixed effects control for important variation in inputs, implying that the divestiturerelated changes we estimate reflect efficiency improvements. In particular, the coefficient on $1[\text { Divested }]_{\text {it }}$ in (3) measures how far the utility owners were from the production frontier, which we define based on the production of the nonutility owners.

After the plant itself, the other important inputs for nuclear power production are labor and fuel, each accounting for about $10 \%$ of the total cost of nuclear power. ${ }^{32}$ Neither labor nor fuel consumption are observed at the plant-level in the United States after the divestitures. In our analysis, industry-wide changes in these inputs are controlled for with the time fixed effects, and time-invariant cross-plant differences are captured with the reactor fixed effects. Divestiture creates incentives for firms to increase output and decrease costs along all margins, including labor and fuel efficiency, so there may have been time-varying, reactor-specific changes in these inputs. Thus, if anything, we are likely underestimating the gains from divestiture by not controlling for reactor-level variation in inputs.

For labor, the available evidence suggests that the amount by which we are underestimating efficiency is small. We do not have a large enough sample to perform a rigorous statistical analysis, but for seven divested plants that we can follow from 1998 to 2002, average employment dropped by 20 percent, while at 24 non-divested plants for which we have comparable data, average employment dropped by 7.5 percent. ${ }^{33}$ This

\footnotetext{
32 Du and Parsons (2009), Table 6C, reports the valuation of cost cash flows at a nuclear power plant by project year and expenditure category. As a percent of total project cost the largest category is construction cost (72\%), followed by labor and other non-fuel operations and maintenance costs (11\%), fuel and waste fees (10\%), and incremental capital costs (7\%). Plant-level data on incremental capital costs are not available. An important exception are investments undertaken to increase the capacity of a plant. The timing of these so called "uprates" are observed and we examine them explicitly in Section 6.

33 The Federal Energy Regulatory Commission (FERC) collects and reports the average employment per year at plants owned by investor-owned utilities, but not at plants owned by independent power producers, making it impossible to use FERC data for such an analysis. Fortunately, during 2001 and 2002 the Department of Energy collected employment information for a subset of U.S. nuclear plants and we have been able to obtain those data and match them with average annual employment from the FERC Form 1.
} 
differential improvement in labor efficiency is consistent with existing evidence of modest labor reductions after divestiture at fossil-fuel-fired plants (Shanefelter 2010). Combining this with national-level data on salaries allows us to approximate the total change in labor expenditures. ${ }^{34}$ In 2009 , the industry employed 62,000 workers at a total cost of $\$ 6.4$ billion (approximately $\$ 103,000$ annually per worker in wages, including bonuses). The plants in our sample employed roughly 800 workers each in the later part of our sample period, so if divested owners reduced their annual wage bill by $15 \%$ more than the utilities, they would save roughly $\$ 12$ million dollars. Given that the average plant has two reactors, this aggregates up to less than $\$ 300$ million in savings across all of the divested reactors. Although substantial, this is small compared to the approximately $\$ 2.5$ billion in additional revenue from increased output.

Aggregate data for uranium fuel consumption suggests that there has not been a substantial change in efficiency along this margin. Between 1994 and 2009 total uranium fuel consumption in the United States increased at almost exactly the same rate as nuclear electric generation. ${ }^{35}$ This suggests that in practice there is little substitution between uranium fuel and other inputs in nuclear power production. Moreover, the marginal cost of uranium is so low relative to wholesale electricity prices that as long as the reactor is available (i.e., not in an outage), the operator should procure fuel to generate as much electricity as possible. More precisely, we are assuming nuclear production is Leontief in the availability of the plant (YAvl), which is a function of capital and labor, and fuel (F): YAct $=$ $\min \left(\mathrm{Y}^{\operatorname{Avl}}(\mathrm{K}, \mathrm{L}), \mathrm{F}\right)$, where $\mathrm{Y}^{\text {Act }}$ is the actual plant output. Marginal fuel costs are so low, however, that the fuel constraint is never binding and YAct $=Y^{\text {Avl }}$. Since YAct is the dependent variable in equation (3), 1 [Divested $]_{\text {it }}$ measures changes in the efficiency of producing availability and is not a function of fuel inputs.

\footnotetext{
34 The Bureau of Labor Statistics' Quarterly Census of Employment and Wages reports state and national information about employment and wages by NAICS code. Nuclear power generation has its own NAICS code (221113) but data is withheld for any geographic industry level in which there are fewer than three firms, effectively preventing these data from being disclosed at the state-level for the nuclear industry.

35 According to U.S. Department of Energy, Energy Information Administration, Uranium Marketing Annual Report, August 2010, the amount of uranium loaded into U.S. nuclear power reactors increased 22\% from 40.4 million pounds in 1994 to 49.4 million pounds in 2009. During the same period according to U.S. Department of Energy, Annual Energy Review 2009, "Table 9.2 Nuclear Power Plant Operations" nuclear electricity net generation increased $25 \%$ from 640 billion kilowatt hours to 799 billion kilowatt hours.
} 


\section{$5 \quad$ Main Results}

\subsection{The Effect of Divestiture on Reactor Efficiency}

Table 3 reports baseline estimates of the effect of divestiture on nuclear operating efficiency. Estimated coefficients and standard errors corresponding to $1[\text { Divested }]_{\text {it }}$ are reported from five separate regressions. The dependent variable in all regressions is net generation as a percent of design capacity (equation 2). Controlling only for month-ofsample fixed effects in column (1), divestiture is associated with a 6.5 percentage point increase in efficiency. As the mean of scaled net generation in our sample for non-divested plants in 2000 was $87 \%$, the increase in divestiture is equivalent to an increase to approximately $94 \%$. The coefficient is statistically significant with a $p$-value less than 0.001 .

Column (2) adds reactor fixed effects and the coefficient increases to 10.4. This increase reflects the fact that the divested reactors tended to underperform relative to other reactors during the extended pre-period, as can be seen in Figure 1. Columns (3), (4), and (5) add reactor age, weight observations by reactor capacity, and collapse the dataset to the plant level, respectively, and the results are similar.

Even with the full set of control variables the $R^{2}$ from these regressions is reasonably low. As we show in detail later in the paper, most of the variation in efficiency comes from reactor outages. The month-of-sample fixed effects capture, for example, that reactor outages tend to peak during particular months of the year, but the low $\mathrm{R}^{2}$ reflects the fact that neither the month-of-sample fixed effects not any other covariate is particularly effective at predicting the exact month in which an outage will occur for a particular reactor.

This is a substantial increase in efficiency. In the United States, nuclear power is a $\$ 40$ billion dollar annual market, accounting for $20 \%$ of total electricity production. ${ }^{36}$ In 2009 , independent power producers in the United States owned 46,649 megawatts of nuclear capacity, so a 10.2 percentage point increase in efficiency implies 42 billion kilowatt hours of additional electricity production. ${ }^{37}$ This is $\$ 2.5$ billion dollars worth of power annually,

\footnotetext{
36 According to U.S. Department of Energy, Energy Information Administration, Annual Energy Review 2009, released August 2010, Table 8.2a “Electricity Net Generation," nuclear plants in 2009 produced 799 out of 3,953 billion kilowatt hours of electricity produced in the United States. In calculating the size of the nuclear power market we assumed an average wholesale price of $\$ 60$ per megawatt hour.

37 U.S. nuclear capacity by producer type is described in U.S. Department of Energy, Energy Information Administration, Annual Energy Review 2009, released August 2010, Table 1.1 "Existing New Summer Capacity." A 10.2 percentage point increase in net generation is $(.102)(46,649)(24$ hours/day)(365 days/year)(1000 kilowatts $/$ megawatt) $=42$ billion kilowatt hours.
} 
almost enough power to meet electricity demand for all the households in New England. ${ }^{38}$

Moreover, this increase in efficiency is large enough to have substantial implications for the environment. Based on average emission levels from the U.S. electricity sector, the increase in operating efficiency associated with divestiture implies an annual decrease of 38 million metric tons of carbon dioxide emissions. ${ }^{39}$ Using a conservative estimate for the social cost of carbon dioxide ( $\$ 20$ per ton) this implies an additional $\$ 760$ million in benefits annually. ${ }^{40}$ To put this into perspective, we are finding that the increase in electricity production associated with divestiture is more than all the electricity produced by U.S. wind and solar generation combined over this period. ${ }^{41}$ This reflects, in part, the fact that there was little U.S. wind and solar generation until the end of the 2000s. However, it also makes the point that even modest improvements in operating efficiency can have substantial environmental implications when that technology makes up a large share of the total market.

These benefits from divestiture must be weighed against several additional costs. The marginal cost of generating power with a nuclear reactor is low, but not zero. Average fuel costs for nuclear power ( $\$ 7$ per $M W h)$ imply an annual increase in fuel expenditures of

\footnotetext{
38 This calculation assumes an average wholesale price of $\$ 60$ per megawatt hour. U.S. Department of Energy, Energy Information Administration, "Wholesale Market Data from Intercontinental Exchange" reports daily average wholesale prices for six major trading hubs. Over the period 2001-2009 the average wholesale price was \$61.00. According to U.S. Department of Energy, Energy Information Administration, "Electric Power Monthly 2010," Table 5.4.B. "Retail Sales of Electricity to Ultimate Customers," residential customers in New England (Connecticut, Maine, Massachusetts, New Hampshire, Rhode Island, and Vermont) consumed 46 billion kilowatt hours of electricity in 2009.

39 From U.S. Department of Energy, Energy Information Administration, Annual Energy Review 2009, released August 2010, Table 12.7a "Emissions from Energy Consumption for Electricity Generation" total carbon dioxide emissions in 2008 for electricity generation were 2.48 billion metric tons. From Table 8.2a "Electricity Net Generation," total electricity generation from fossil fuels was 2.73 trillion kilowatt hours. Thus 42 billion kilowatt hours of fossil fuel-based power implies $(2.48)(42)(1,000,000) /(2.73)=38$ million metric tons of carbon dioxide emissions. In practice increased nuclear production will displace whatever form of power production is marginal in a particular market during a particular day and hour. However, modeling all the different wholesale markets in the United States at an hourly level during this 10+ year period since deregulation goes beyond the scope of the analysis.

40 Federal Interagency Working Group (2010) presents a range of values for the social cost of carbon dioxide according to different discount rates and for different time periods that is intended to capture changes in net agricultural productivity, human health, property damages from increased flood risk, and other factors. In Table 15A.1.1 with a 3\% discount rate (their "central value") for 2010 they find a social cost of carbon dioxide of $\$ 21.40$ (in 2007 dollars) per metric ton of carbon dioxide. In 2010 dollars this is approximately \$22.

41 According to U.S. Department of Energy, Energy Information Administration, Annual Energy Review 2009, released August 2010, Table 8.2a "Electricity Net Generation," during the period 2000-2009 U.S. wind and solar generation combined averaged 26 billion kilowatt hours annually. The average total capacity of divested reactors over the same period is 36,517 megawatts so a 10.2 percentage point increase in net generation is $(.102)(36,517)(24$ hours/day)(365 days/year)(1000 kilowatts/megawatt) $=32$ billion kilowatt hours annually.
} 
approximately $\$ 300$ million. ${ }^{42}$ An additional potential cost is labor, though as we described earlier in the paper, the available data suggest that, if anything, the number of workers in divested reactors has actually declined relative to utility reactors. Storing the additional spent uranium fuel creates additional costs. It is difficult to quantify the external costs of the additional spent fuel but available estimates in the literature indicate that the private costs of dry cask storage are small. ${ }^{43}$ Finally, companies with substantial inframarginal generating capacity, including nuclear reactors, find it more profitable to exercise market power. ${ }^{44} \mathrm{~A}$ comprehensive accounting of the costs and benefits of divestiture would need to include these additional costs, as well as additional benefits such as decreased emissions of local pollutants, and, in the long-run, decreased investment in new generating capacity. 45

\subsection{Heterogeneous Effects}

Table 4 reports estimates from four separate regressions which describe the effect of divestiture by reactor design, reactor manufacturer, reactor vintage, and type of sale. In each case the indicator variable $1[\text { Divested }]_{i t}$ is interacted with indicator variables for the different categories as listed in the row headings. The estimated coefficients on these interaction terms are positive in all eleven cases and statistically significant at the $1 \%$ level in ten out of eleven cases. In none of the four regressions can one reject the null hypothesis

42 MIT (2009) reports fuel costs of $\$ 7$ per MWh for nuclear power based on fuel prices of $\$ 0.67$ per million BTU and average heat rates of 10,400 BTU per kilowatt hour. A 42 billion kilowatt hour increase would then imply $\$ 294$ million annually in additional fuel expenditures.

${ }^{43}$ In the United States there is no federal spent fuel storage facility and no facilities for the reprocessing of spent fuel. Currently, spent fuel is stored on site in storage pools or, increasingly, in dry cask storage. According to U.S. NRC, Information Digest 2010-2011 NUREG-1350, Volume 22, published August 2010, the total amount of spent fuel in the United States increases by 2,000 tons annually, so a $10 \%$ increase in spent fuel from half of the nation's reactors is approximately 100 tons annually. A 2008 report commissioned by the U.S. Department of Energy reports that private lifetime costs for dry cask storage including licensing, construction, procurement, loading, and maintenance are $\$ 120$ per kilogram which (ignoring any potential economies of scale) implies $\$ 11$ million in additional costs. See Idaho National Laboratory, Advanced Fuel Cycle Cost Basis INL/EXT-07-12107, Module E2 "Dry Storage of Spent Nuclear Fuel" for details.

${ }^{44}$ A precise modeling of the relevant wholesale markets, participants' contractual positions, and the extent to which the divestitures increased the incentive of participating companies to exercise market power goes beyond the scope of the paper.

45 In future work it would also be interesting to examine the distribution of these costs and benefits. The environmental impacts accrue globally for carbon dioxide, regionally for criteria pollutants, and locally for changes in storage of spent uranium fuel. The private benefits of operating efficiency, however, are shared primarily between ratepayers and shareholders, with the exact division of gains depending on how electricity prices were impacted. In a perfectly competitive market, increased production from nuclear reactors shifts the supply curve for electricity to the right, replacing higher-cost forms of generation and decreasing average wholesale electricity prices. Exactly how much electricity prices have actually come down is an empirical question that depends on demand- and supply-side factors. 
of equal coefficients. The uniformity of the results across columns (1-3) indicates that the efficiency gains were experienced broadly across different types of reactors.

The regression in column (4) tests whether efficiency gains differed depending on the type of sale. Of the 48 total divestitures, 19 (40\%) were external sales in which reactors were sold to the highest bidder. With the other 29 divestitures, reactors were sold to independent power producers that were affiliated with the original owners. One might have expected external sales to lead to increased efficiency gains due to superior matching of operators to reactors. The results in column (4) provide some suggestive evidence for this hypothesis, but the point estimates for both types of sales are large, positive, and statistically significant.

Figure 2 plots point estimates and $95^{\text {th }}$ percentile confidence intervals for a regression that allows the effect of divestiture to differ across calendar months. All twelve coefficient estimates are positive and statistically significant at the $5 \%$ level. The largest point estimates are for May and November -- historically the peak months for refueling shutdowns because of the relatively low level of electricity demand. During these months there is more scope for increasing efficiency compared to, for example, the peak summer months when most reactors were running at close to full power even prior to the divestitures.

\subsection{The Effect of Consolidation on Reactor Efficiency}

The divestitures between 1999 and 2007 transferred operation of many reactors from companies subject to traditional cost-of-service regulation to independent power producers selling power in competitive wholesale markets. At the same time, however, the divestitures consolidated reactor operations among a smaller set of companies. Economists have long recognized the potential efficiency gains from consolidation in the nuclear power industry. Joskow (1982) explains,

"The way reactors are built and operated must be changed... At present, more than forty utilities have nuclear-power plants operating or under construction. Some of these utilities are very large, while others are very small. It is at least arguable that there are opportunities for economies of scale in the construction and safe operation of nuclear facilities that are not being exploited because of the fragmented ownership pattern that flows 
from the present structure of the electric-utility industry in the United States." (page 250)

Figure 3 describes consolidation in U.S. nuclear power operation over the period 1970-2009. We calculate for each reactor-month the number of other reactors operated by each reactor operator. The figure plots annual means of this variable separately for those reactors that were divested 1999-2007 and all other reactors. The figure illustrates how divestitures have led to an unprecedented degree of consolidation in the industry. As late as the mid-1990s, there was relatively little consolidation. The average reactor was operated by a company that operated less than three other reactors, and most reactors were operated by companies that operated only one or two other reactors. By the end of 2009, however, reactors were operated by companies that operated an average of more than six other reactors and the three largest companies (Entergy, Exelon, and NextEra) operated about one-third of all nuclear capacity in the United States.

In principle, consolidation could improve operating efficiency in several ways. Whereas a utility with a single reactor may rely on contract employees to perform infrequent tasks, such as refueling outages, which take place on average every eighteen months, a consolidated nuclear company can hire highly skilled employees and train them to appreciate the idiosyncrasies of the company's reactor fleet. A chairman of a major nuclear company explains, "you need to have a significant number of highly qualified staff across all the range of disciplines, and it's more cost-effective to service a number of plants than to service a single plant." 46 Also, within a consolidated company, employees can disseminate best practices for refueling and maintenance. ${ }^{47}$ These effects are in addition to incentives created by a divestiture, in which the operator, regardless of its size, becomes the residual claimant on any revenues earned from increased efficiency.

It is instructive to consider the variation in our data that will help distinguish a consolidation effect from the divestiture effect. First, there were many changes in operators that were not associated with divestitures but that changed the level of consolidation in the

46 Robin Jeffrey, deputy chairman of British Energy quoted in "Shut Down: Can Nuclear Plants Survive Deregulation? The Jury is Still Out," Wall Street Journal, September 14, 1998. British Energy purchased several plants in the United States including Clinton and Three Mile Island 1 through a joint venture with Amergen.

47 Anecdotal evidence suggests that this has indeed occurred. Gary Leidich, the president of FirstEnergy Nuclear described the company's acquisition of three nuclear plants as follows. "It was three separate facilities, each pretty much doing their own thing. Now it's a corporate organization with a fleet approach." Quoted in "Executive Vows Strong Focus on Plant Safety" in The Plain Dealer, Cleveland Ohio, March 9, 2004. This fleet approach means, for example, that plant operators have a daily 7:30 a.m. conference call for discussing potential problems and managers at FirstEnergy travel from plant to plant. 
industry. For example, when Toledo Edison, Duquesne Lighting Company, and Centerior were combined to form First Energy in 1997, the four reactors operated by those companies may have experienced improved operations. Second, there are several reactors that are operated by companies that control both divested and cost-of-service regulated, utility reactors. For example, Entergy began as a Southern investor-owned utility and continues to operate reactors in Arkansas, Mississippi, and Louisiana. As of 2009, Entergy operates eleven reactors, five of which are located in these Southeastern states which have not restructured their electricity markets. This explains why the pale line in Figure 3, reflecting the average number of reactors operated by operators of non-divested reactors increased after 2000. It is possible that these plants benefited from Entergy's acquisition of the divested plants, through the mechanisms we identified above.

Table 5 reports regression estimates. Column (1) presents the baseline estimate, identical to the third column in Table 3. In column (2), we expand the estimating equation to include our consolidation variable. The coefficient estimate on consolidation is 0.48 , implying that increasing by one the number of other reactors operated by the same operator improves efficiency by about half a percentage point. ${ }^{48}$ Although the coefficient is estimated with some noise ( $p$-value 0.09 ), the point estimate is large enough to be economically important. The range of the consolidation variable is 0 to 16 so the point estimate implies that a change from the minimum to the maximum for this variable would increase efficiency by 7.7 percentage points, an effect about as large as the point estimate on $1[\text { Divested }]_{\text {it }}$.

Columns (3) and (4) report results from alternative specifications using narrower measures of consolidation. One might have expected economies-of-scale in operation to be particularly large for companies that own multiple reactors of the same type (pressurized water versus boiling water) or manufactured by the same firm. Accordingly, in these specifications consolidation is measured using only reactors of the same type or manufacturer, respectively. The point estimates are similar to the point estimate in column (2) suggesting that the gains from consolidation come from broad changes in operations and maintenance, rather than from specific changes related to the technical characteristics

\footnotetext{
48 In alternative results not reported we tested for nonlinear effects by including a square term and by allowing for different bins $(0-4,5-8,9-12$, and 13-16) and in neither case do we find evidence of a nonlinear effect.
} 
of particular reactor designs. ${ }^{49}$ It is difficult to draw strong conclusions, however, because the parameter estimates are again imprecisely estimated.

We performed several robustness checks to verify our interpretation of these results. First, while the variation in our data allows us to estimate both a divested and a consolidation effect, the degree of consolidation is certainly higher among divested plants, as depicted in Figure 3. In column (5) we re-estimate the specification reported in column (2) using only reactors that were never divested and dropping the divestiture indicator variable. The coefficient on the number of reactors controlled by the same operator is larger than the coefficient reported in column (2) and statistically significant ( $p$-value 0.016), suggesting that gains from the large divested companies are not biasing the coefficient estimate upward.

Finally, in column (6) we collapse our data to the plant level and estimate spillovers from an operator having an additional plant in its fleet. The effect is nearly twice as large as the estimated effect in the reactor-level regression, reflecting that the typical reactor is housed at a two-reactor plant so that the mean of the consolidation variable in the plantlevel specification is about half as large. In the plant-level regression the coefficient on the consolidation variable is statistically significant at the two percent level ( $p$-value 0.013$).{ }^{50}$

In additional unreported results we also considered a number of specifications aimed at assessing potential interactions between divestiture and consolidation. When we include an interaction term between divestiture and consolidation the point estimates on both the interacted and uninteracted consolidation terms are positive but neither are statistically

\footnotetext{
49 In related work, Lester and McCabe (1993) compare operating efficiency of U.S. and French nuclear reactors. In part because the United States was a pioneer in nuclear power generation, there was a great deal of technological advancement and learning during the period reactors were being built, and consequently there are many different designs, even among reactors by the same manufacturer. In contrast, France adopted a single reactor design (essentially a copy of the Westinghouse pressurized water reactor) and 58 out of 59 French reactors operating as of 2009 are this same type (International Atomic Energy Agency, 2010, Nuclear Power Reactors of the World, Table 14). Lester and McCabe argue that this standardization has increased learning-bydoing in plant operation and test empirically for differential learning-by-doing among reactors of different designs.

50 An interesting question is whether these efficiency gains could have been realized through operating contracts, perhaps with only a few highly consolidated operating companies nationwide. Testimony from Exelon before the New Jersey Board of Public Utilities in 2005 about a proposed merger with PSEG suggests that the answer is no. "The Operating Services Agreement (OSA) does not provide sufficient financial incentive for Exelon to agree to a similar agreement in the absence of the merger. The OSA diverts significant Exelon management attention from other business opportunities... and does not allow Exelon sufficient financial incentive or operational control to bring Salem and Hope Creek performance up to Exelon's fleet-wide performance levels. In short, if it had made business sense for Exelon and PSEG to enter into an OSA in the absence of a merger, than we would have done so a long time ago."
} 
significant. We also tested for a change in operating efficiency among non-divested reactors when reactors operated by the same company are divested. If there are spillovers within companies then one might have expected an increase in operating efficiency among these reactors. On the other hand, if companies are able to shift resources, such as skilled operators, between divested and non-divested reactors, then one might have expected a decrease in operating efficiency. In the regression the estimated effect of divestiture on nondivested reactors is small and not statistically significant, providing no evidence for either hypothesis. However, there are only nine non-divested reactors operated by companies that operate at least one divested reactor so these results are too imprecisely estimated to draw strong conclusions.

Much of the consolidation in the U.S. nuclear industry has occurred through the growth of particular companies, including Exelon and Entergy. Although the results in Table 5 are consistent with economies of scale, it could also be that there is persistent heterogeneity in management quality across companies and that divestiture has reallocated plants to companies with more effective managers. In alternative, unreported results we include indicator variables for Exelon, Entergy, and NextEra (the three companies that own the most U.S. reactors as of 2009 - collectively over one third of all reactors). ${ }^{51}$ The estimated coefficient corresponding to divestiture remains large and highly statistically significant. The point estimate on consolidation is essentially unchanged but the standard error grows considerably.

Overall the results provide some mild evidence of efficiency gains from industry consolidation. The point estimates corresponding to the consolidation measure are only statistically significant in columns (5) and (6) but are consistently positive and large enough to be economically important. Also interesting is that the estimate corresponding to divestiture is consistently large, statistically significant, and reasonably similar across specifications, indicating that it is divestiture and not consolidation driving the large share of the efficiency gains.

\footnotetext{
${ }^{51}$ Interestingly, prior to deregulation there is little evidence that these companies were the best-managed. The three largest U.S. nuclear companies as of 2009 are Exelon (formerly Commonwealth Edison), Entergy, and NextEra (formerly FPL Group). Between 1990 and 1998, reactors owned by these three companies had lower operating efficiency on average than other U.S. reactors.
} 


\subsection{Considering Possible Concerns about Selection Bias}

This subsection evaluates potential concerns about selection bias and differential trends in operating efficiency. From an empirical design perspective, the ideal experiment would be to take the entire population of nuclear reactors and then randomly select a subsample of reactors to divest. From the mean characteristics reported in Table 2 is it clear that the recent experience in the U.S. nuclear industry falls short of this ideal. Our preferred specification includes reactor fixed effects which control for observed and unobserved mean differences between reactors. Still, one could be concerned that the reactors that were divested had different pre-existing trends. One possibility, for example, would be that reactors were selected based on which reactors stood the most to gain from restructuring. Although it is impossible to completely rule out these concerns, there are several features about how deregulation occurred in practice that substantially decrease the scope for selection bias in this context.

First, in almost all cases decisions about divestiture were made at the state level, not at the reactor level. In all but one state, either all of the state's nuclear reactors were divested or none of the state's reactors were divested. The one exception is the state of Michigan, where one reactor was divested but the other three reactors were not. Given that Michigan is an unusual case, we find it reassuring that our results are essentially identical when the four reactors in Michigan are excluded from the sample. See column (1) in Table 6.

Second, almost all nuclear reactors were divested in states where deregulation occurred. The fourteen states that have deregulated their electricity markets (as of 2011) are Connecticut, Delaware, Illinois, Maine, Maryland, Massachusetts, Michigan, New Hampshire, New Jersey, New York, Ohio, Oregon, Pennsylvania, and Texas. With the exception of Michigan, all of the nuclear reactors in all of these states have been divested. An interesting case is California which divested a substantial amount of the fossil-fuel-fired power plants in the late 1990s before suspending deregulation after the California Energy Crisis in 2000. Neither of the state's two nuclear power plants (Diablo Canyon or San Onofre) have been divested, potentially raising concerns about selection. Again, however, 
we find it reassuring that excluding these reactors from the sample the estimated coefficient is essentially unchanged. 52 See column (2).

Third, in states where electricity deregulation did not occur, nuclear reactors were not divested in almost all cases. Here the two exceptions are Iowa and Wisconsin. These states did not deregulate their electricity markets but have divested a considerable fraction of their generating facilities. Once again, however, when these reactors are dropped from the sample the coefficient estimate corresponding to $1[\text { Divested }]_{\text {it }}$ is essentially unchanged. See column (3).

Fourth, most of the divestitures occurred over a relatively short period of time so differential timing of divestitures cannot explain the results. Of the 48 reactors that were divested, 36 were divested during a three and a half year period between July 1999 and November 2002. When we re-estimate the model using January 1, 2001 as the divestiture date for all divested reactors, the estimated coefficient on $1[\text { Divested }]_{\text {it }}$ is smaller (consistent with attenuation bias), but still positive and statistically significant (7.9 with a tstatistic of 3.31). See column (4).

Thus there is a strong but not perfect correlation between deregulation and nuclear divestitures. Although this greatly reduces the scope for reactor-by-reactor selection bias, it raises the broader question of whether state-level decisions about whether to deregulate or not were influenced by potential efficiency gains in nuclear reactors, or whether these decisions were driven by some other factor that is correlated with trends in operating efficiency. Again it is impossible to completely rule out these concerns but the existing literature about the determinants of deregulation provides an important point of reference.

\footnotetext{
52 California is also an interesting case because of the experience with incentive regulation described in Section 2.2. Throughout the analysis, the comparison group in our regressions includes nuclear plants subject to traditional cost-of-service regulation as well as plants operating under different forms of incentive regulation. Sappington (2001) identifies 16 states in which electric utilities were operating as of 2001 under some form of incentive regulation. Only 10 of the states have nuclear reactors. When we reestimate the model using as a comparison group only reactors operating in these 10 states the estimate is 10.1 (3.0). This suggests that the divestiture gains are no smaller when compared to reactors facing incentive regulation, consistent with a small existing literature (e.g. Verma, Kitna, and Marcus, 1999) that finds little robust evidence that incentive regulation increases operating efficiency. Whereas after divestiture there is no question about who is the residual claimant for future operating profits, it may be difficult for public utility commissions to credibly commit to incentive-based programs as was ultimately the case with the California Public Utility Commission and the Diablo Canyon plant.
} 
Deregulation came out of a broader discussion about the electricity market as a whole, including all forms of generation, unbundling transmission and distribution, and introducing retail choice. The idea that competition would create incentives for more efficient operation of nuclear power reactors was only one small piece of this larger discussion. A number of studies have examined the determinants of deregulation and determined that the best predictors are liberal politics and high electricity prices (see, e.g., White 1996). Differences in electricity rates across states have much more to do with the type of generating equipment in each state's generation portfolio, rather than the efficiency with which it is operated. For example, utilities with access to federally subsidized hydropower typically have lower rates than other utilities. And again, our preferred specification includes reactor fixed effects which control for time-invariant differences across reactors and the states in which they are located.

In practice there is a distinct geographic pattern to deregulation, with most divested reactors in the Northeast and most non-divested reactors in the South. Is there something different about reactor operation in these different regions? For example, could the weather in the Northeast region be more conducive to increasing efficiencies above $90 \%$ ? The answer is probably not. Outdoor temperature, or more importantly, the temperature of cooling water, does affect electricity production, but within the relevant range of temperatures the effect is too small to matter. Moreover, the daily data show that divested reactors have fewer outages throughout the year, not just during the winter. This finding would be difficult to reconcile with some region-specific climate-driven factor. Columns (5) and (6) present additional robustness tests, excluding from the regression all reactors in the Northeast and weighting never-divested reactors using propensity weights. ${ }^{53}$ Point estimates in these specifications are again very similar. Both specifications are demanding tests of the data which require excluding more than half of the divested reactors from the sample and the fact that the point estimates are again positive and statistically significant at the $1 \%$ level provides additional evidence that the observed efficiency gains are not driven by selection.

\footnotetext{
53 The idea of propensity score weighting is to reweight the observations in the comparison group to balance the mean characteristics of divested reactors. Propensity scores were estimated using a logit regression where the dependent variable is an indicator variable for reactors that were ever divested. Regressors include mean design capacity, reactor age as of December 1998, and indicators for reactor type, manufacturer, and census region. This specification necessarily excludes all reactors in the Northeast census region where all reactors were divested as well as all reactors in the West census region where none of the reactors were divested.
} 
The specifications described in columns (7)-(10) are aimed at assessing potential related concerns about long outages during the period 1996-1998 that cause the pronounced "dip" in efficiency in Figure 1. The point estimates drop somewhat in these specifications but remain large and highly statistically significant, providing evidence that the baseline estimates are not driven by these long outages. It is not surprising that point estimates are smaller in these regressions because they exclude periods of unusually poor operating efficiency among divested reactors prior to divestiture. We include the long outages in our main results as they are part of the divestiture effect we seek to measure. Deregulation changes incentives, making reactor operators financially responsible for long outages such as these. For an independent power producer, the financial implications of a $12+$ month outage are devastating, and we do not think it is a coincidence that the incidence of outages has decreased substantially among divested reactors. In the following section we turn to daily data on reactor status which allows us to examine these outages explicitly.

Finally, column (11) addresses potential bias related to plant closures during the 1990s. An attractive feature of the analysis is that there is very little entry or exit during the period of divestitures, substantially mitigating concerns about selection bias. ${ }^{54}$ One could potentially be concerned, however, about differential closures during the years leading up to the period of divestitures. Between 1993 and 1998, five full-scale (100MW+) commercial reactors were closed, all located in states that subsequently deregulated their electricity markets and divested nuclear plants. ${ }^{55}$ It is possible that impending divestitures encouraged owners to close plants at which they expected performance to degrade while comparable plants in non-divesting states remained open. Over their lives, the five closed plants did not have particularly low output. In fact, their average through 1995 was slightly higher than all divested reactors, but they were distinctly worse (six percentage points) than divested reactors in the first half of 1990s. To bound the possible bias introduced by the closure of these five reactors, we matched them with reactors of similar vintage and size that were not divested. We then calculated changes in net output from the fifteen years before the closure to the fifteen years after for the matched sample, and used those changes to impute postclosure output from the five reactors based on their fifteen-year average net output before

\footnotetext{
54 Since 1998 no nuclear reactors have been closed in the United States, and the only "opening" is Browns Ferry 1 which reopened in 2007 after an outage that lasted more than two decades. Between 1970 and 1998, 20 reactors were closed, though nearly half of these closures were small experimental reactors.

55 The five plants were Maine Yankee (Maine), Haddam Neck and Millstone 1 (Connecticut) plus Zion 1 and Zion 2 (Illinois).
} 
the close. These estimates, therefore, reflect what would have happened to the plants had they been operated similarly to the plants of similar vintage and size in states that did not divest. The coefficient on 1 [Divested $]_{\text {it }}$ declines slightly to 8.6 percentage points, suggesting that the decisions to close reactors, even if related to the impending divestitures, likely does not explain much of the estimated divestiture effect.

\section{Understanding the Mechanisms behind Post-Divestiture Gains}

\subsection{Mechanisms - Graphical Analysis}

We next turn to ancillary evidence aimed at understanding the mechanisms driving this observed increase in efficiency. One possible explanation is that divested reactors may have been more likely to increase their maximum generating capacity. U.S. nuclear power reactors are licensed with the NRC to operate at a particular maximum heat level. However, plant operators can petition to have this maximum thermal capacity increased. This is known as an "uprate."56 Since 1970 nuclear uprates in the United States have added 6,000 megawatts of total electric capacity -- the equivalent of 6 new 1000 megawatt reactors.

Figure 4 plots mean licensed thermal capacity for divested and non-divested reactors over the period 1970-2009. The sample of reactors here and throughout the analysis in this section is again all reactors that were operating as of January 1, 2000. Capacity is expressed as a percent of the original license. During the early 1970s all reactors operated at their original licensed capacities. During the late 1970s, 1980s, and 1990s, there were 4, 10, and 33 total uprates, respectively. Uprates increase sharply beginning around 2000, and there are 81 total uprates between 2000 and 2009.57 Independent power producers have been more likely to perform uprates, though investor-owned utilities have been active as well. In Section 6.2 we turn to a regression analysis with these same data in order to determine whether the difference in uprates is statistically significant after controlling for covariates.

Other possible explanations for the increase in operating efficiency include an increase in operating days or an increased capacity factor when operating. In order to

\footnotetext{
56 Nuclear thermal capacity can be increased by using highly-enriched uranium or by reducing the use of materials that moderate the nuclear reaction. Typically nuclear fission is moderated using control rods made of boron or other elements which absorb neutrons.

57 Technological advances in fuel rod construction provide part of the explanation for why uprates have become more common since the 1990s. Innovations in metallurgy have increased the thermal capacity of fuel rods, allowing them to run hotter without leaking radioactivity.
} 
examine these mechanisms we turn to the daily data from the NRC. Whereas the analysis in Section 5 uses monthly data for a 40-year period 1970-2009, these daily data are available only for 1999-2009. This makes this alternative dataset less useful for the primary empirical exercise in the paper - constructing a counterfactual for how reactor efficiency in divested reactors would have evolved in the absence of divestiture. Nonetheless, the fact that these data are available at a very high frequency makes them particularly valuable for examining reactor outages.

Figure 5 plots the fraction of U.S. reactors not operating by day over the period 19992009. The figure reveals a pronounced seasonal pattern of outages. Each year outages peak twice, once during the spring and again once in the fall. At the peaks between $15 \%$ and $30 \%$ of reactors are not operating during a given day. At the troughs, less than $5 \%$ of all reactors are not operating. Figure 6 investigates this pattern further, illustrating how the fraction of reactors not operating by day has changed over time. Mean outages are plotted separately for divested and non-divested reactors. At the beginning of the sample the annual pattern for both groups is reasonably similar but by the end of the sample outages are considerably less frequent among divested reactors. This holds for almost all days during the entire year, with particularly large differences during the late spring and late fall.

Figures 7 and 8 provide additional evidence about the pattern of outages over time. The first figure plots the mean number of outage days per year 1999-2009. Both time series are relatively noisy but it is interesting that mean outages among divested reactors is below mean outages among all other reactors for every year between 2004 and 2009, with some suggestion that the gap may be increasing over time. Figure 8 plots the mean number of scrams per hour of reactor operation. There is a substantial and reasonably steady decrease in scrams industry-wide, and little evidence of a divergence between divested and nondivested reactors. In the following subsection we estimate regressions which allow us to test whether divestiture has had a statistically significant impact on either measure.

While divested reactors appear to have fewer outages, during operation they do not appear to be operating at a higher capacity factor. Figure 9 plots mean capacity factor by day of year for operating reactors. Divested and non-divested reactors follow a very similar pattern, peaking in the winter and summer when almost all reactors are operating at full power. Across all days 2005-2009 mean capacity factor for operating reactors is almost exactly identical for both groups, 97.96 for divested reactors versus 98.02 for non-divested 
reactors. ${ }^{58}$ These high capacity factors reflect the fact that, when operating, nuclear reactors are typically run at full power. A large fraction of the observations of capacity factor that are below 100\%, moreover, are from reactors that are ramping down to or out of outages rather than reactors that are being consistently run below $100 \%$. The seasonal pattern makes sense when interpreted in this context because the somewhat lower capacity factors during spring and fall are during the periods in which outages are more common, and thus a larger fraction of operating reactors are ramping up and down.

\subsection{Mechanisms - Regression Analysis}

Table 7 reports regression estimates that complement the graphical analysis in the previous subsection. These ancillary regressions continue to tease out the mechanisms driving the increase in efficiency post-divestiture. Regression estimates corresponding to an indicator variable for reactors that have been divested are reported for seven different dependent variables including maximum capacity, the number and length of reactor outages, and capacity factor while operating. Overall, the regression results are consistent with the basic pattern of behavior observed in the graphical analysis.

Panel (A) examines maximum generating capacity. Regression coefficients are reported for two different measures of capacity and for three different specifications which add control variables as one moves from left to right. In the first row the dependent variable is the maximum observed level of net generation over the previous twelve operating months as a percentage of reactor design capacity. In the third column, controlling for reactor fixed effects and reactor age, divestiture is associated with a 1.7 percent increase, although the coefficient is not statistically significant. The second measure of capacity is licensed maximum thermal capacity. As described above, plant operators can petition to have their maximum thermal capacity increased, and the regression estimates in this row can be seen as a test of whether divested plants were more likely to perform uprates. The coefficient estimates in this row are similar in magnitude to the coefficients in the first row, but again not statistically significant.59 Viewed together with Figure 4 the regression

\footnotetext{
58 In interpreting these means it is important to keep in mind that capacity factor is measured relative to maximum thermal capacity and that divested reactors have been more likely than other reactors to receive uprates. The fact that divested reactors appear to be operating at approximately the same percentage of a higher maximum capacity implies a higher level of total electricity generation.

59 One notable feature of Figure 4 is that during the late 1990s the mean thermal capacity among subsequently
} 
estimates in these two rows provide suggestive evidence of a relationship between divestiture and increases in generating capacity.

Modest uprates (2-3\%) can be performed with little or no equipment replacement, but larger uprates typically require modifications to non-nuclear equipment such as high-pressure turbines, condensate extraction pumps, motors, and transformers. The cost of these modifications ranges from $\$ 750$ to $\$ 900$ per kilowatt of added capacity. 60 Thus, a large (e.g. 8\%) uprate for the median-sized reactor in our sample (794 MW) could cost $\$ 50$ $\$ 60$ million. Although not negligible, this is small compared to the value of the increased electrical generation and tiny compared to the cost of building a new nuclear reactor.

Panel (B1) focuses on reactor operating days and shutdowns. The first dependent variable is an indicator variable for whether the reactor is operating. In our sample this is 91\% of all reactor-day observations. The estimated coefficients in this row range from 3.5 to 3.9 percent. This is a large effect relative to the mean, implying that divestiture is associated with a decrease in outages of about one-third, equivalent to an increase of 13-14 operating days per year per reactor. These results are consistent with the graphical analysis above and indicate that the pattern of decreased outages observed in Figures 6 and 7 remains after controlling for the available covariates. ${ }^{61}$

Although they represent a small share of total outages, automatic shutdowns or "scrams" are particularly interesting because they have been used in previous studies as a measure of reactor safety (see, for example, David, Maude-Griffin, and Rothwell 1996). All

divested reactors appears to lag behind the mean thermal capacity for all other reactors. This corresponds with the period of long outages discussed in Section 4.1 and 5.4. The capacity increases among divested reactors do not appear during or immediately after these outages. Indeed it is not until 2001 and 2002 that the large uprates are observed in Figure 4. As a robustness check, we have also estimated the regressions in panel (A) excluding 1995-1998 and the results are almost identical.

60 This cost range comes from Tom Weir, the Senior Vice President for Engineering at Framatome ANP (now Areva), a leading international nuclear firm as quoted in Fabian, Thecla, "New Plant from Old," Nuclear Engineering International, September 12, 2005. At $\$ 900$ per kilowatt of added capacity, typical average wholesale electricity prices ( $\$ 60$ per $\mathrm{MWh}$ ), and a $90 \%$ capacity factor a reactor owner would pay for the investment in about 2 years.

61 We also tested whether divested reactors are systematically more likely to be operating when wholesale electricity prices are high. Using daily data from U.S. Department of Energy, Energy Information Administration, "Wholesale Market Data from Intercontinental Exchange" for six major trading hubs from 2001-2009 we estimated alternative specifications with the divestiture indicator, the wholesale price, and the interaction between the two. Including these additional covariates has essentially no impact on the estimated coefficient for divestiture and the estimated coefficient corresponding to the interaction term is close to zero and not statistically significant. From Figure 5 it is clear that both investor-owned utilities and independent power producers tend overwhelmingly to perform refueling and maintenance during the spring and fall when wholesale prices are low. Given that outages are already being performed during these periods and that most outages are planned long in advance, there seems to be little scope for increased efficiency along this margin. 
three point estimates in this row are negative. The coefficients in the second and third columns are not statistically different from zero ( $p$-value .09 for both), but are estimated with enough precision to reject increases larger than 5\%.62 Moreover, these point estimates are large compared to the mean, implying a 30\% decrease in scrams after divestiture. This is consistent with a widely-held view in the nuclear industry that there are complementarities between safety and operating efficiency. ${ }^{63}$ Profit maximization requires that reactors run reliably for thousands of hours a year, and component failures and other forms of unplanned outages are bad for both safety and profits. This is true both in the short-run and in the long-run, as reactors with poor safety records receive increased regulatory scrutiny and an increased probability of extended safety-related shutdowns. It is important to keep in mind, however, that this is only one, highly-imperfect, measure of nuclear reactor safety so these results should be interpreted with caution.

Panel (B2) pushes further on reactor outages - asking whether the decrease in outage days is being driven by fewer or shorter outages. In the third column, divestiture is associated with an $8 \%$ decrease in the number of outages per year, and a $36 \%$ decrease in the mean outage length, but neither are statistically significant. ${ }^{64}$ The lack of precision makes it impossible to make definitive statements but it appears that outage length may be the more important of the two. Taking the point estimates literally, a reduction of 6.9 days per outage multiplied by the mean number of outages per year (1.7) yields a reduction of almost 12 outage days per year, whereas a reduction of .13 outages per year multiplied by the mean outage length (19.1) yields a reduction of only 2.5 outage days per year.

Finally, Panel (C) examines capacity factor conditional on operating. Consistent with the graphical analysis above, the regression estimates in this row provide no evidence that reactors that have been divested are operated at higher intensity when they are operating.

\footnotetext{
62 Hausman (2011) finds similar results examining a variety of different safety measures including "initiating events" of which scrams are a subset.

63 For example, Hubert Miller of the NRC explains, "Most people have gotten the understanding if you... emphasize safety and managing things better, it has a positive effect on the bottom line," as quoted in Matthew L. Wald "Despite Fear, Deregulation Leaves Nuclear Reactors Working Harder, Longer, and Safer," New York Times, February 18, 2001.

64 An alternative would have been to model outage length using a duration model. For instance, we could have used a Cox proportional hazard model to describe the probability than an outage ends. The advantage of least squares, however, is that it is more transparent and requires weaker identifying assumptions. Duration models are particularly well suited for contexts in which there is a large amount of censoring. Outages are relatively short and frequent compared to the sample length so this is not particularly important. A duration model would also allow us to examine how the probability that an outage finishes varies with the duration of the spell (e.g. positive or negative duration dependence), but again this is not particularly important in this context.
} 
After adding reactor fixed effects the estimates are positive but small in magnitude and not statistically significant.

In summary, Table 7 describes three possible mechanisms that could lead to increased monthly generation at divested reactors. A reactor will generate more electricity if it produces more when at maximum capacity (panel A), is available more days (panel B), or produces at a higher capacity factor when available (panel C). The results suggest that the increase in operating efficiency is primarily explained by the first two channels: an increase in maximum capacity and a decrease in outages. These two factors together imply a total increase in efficiency about as large as the baseline estimate in Section 5.65

\section{$7 \quad$ Conclusion}

This paper examines an unprecedented period of deregulation and consolidation in the U.S. nuclear power industry. We analyze operating efficiency before, during, and after market restructuring using a unique, high-quality dataset that describes reactor-level operations over a 40-year period. We find that deregulation and consolidation are associated with a $10 \%$ increase in operating efficiency, with similar increases across reactors of different types, manufacturers, and vintages. This central result is robust across a variety of alternative sets of control variables and specification checks. In additional analyses aimed at understanding the mechanisms driving these results we show that the increase in operating efficiency has occurred, most importantly, by decreasing the number of outage days per year.

These results provide some of the clearest evidence to date of efficiency gains from the deregulation of electricity markets. As predicted by economic theory, removing regulation has provided incentives for firms to increase efficiency, reduce costly outages, and make prudent investments in capacity. As plants have been sold to private companies the financial cost of poor operating efficiency has transferred from ratepayers to shareholders, and companies like Exelon and Entergy have responded by achieving the highest levels of nuclear reactor operating efficiency in history. Each additional operating

\footnotetext{
65 The total increase in operating efficiency implied in Table 7 is similar to the point estimate in column (1) of Table 3. The point estimates in columns (2-5) of Table 3 indicate a somewhat larger total increase in part because with the longer pre-period available in the monthly data once reactor fixed effects are included the coefficient estimates are larger, reflecting the fact that divested reactors tended to underperform during the 1980s and 1990s.
} 
hour for a typical nuclear power plant represents about $\$ 120,000$ in profit - and these companies have worked hard to make sure their plants are operating as much as possible.

Our paper also highlights an important relationship between nuclear operating efficiency and the environment. We find that over this period the increase in electricity production from nuclear plants associated with divestiture implies more carbon abatement than all U.S. wind and solar generation combined. This reflects the fact that nuclear generation represents a large share of the electricity market, particularly compared to wind and solar which are growing but continue to represent a relatively small share. Nonetheless, one of the broader lessons from our analysis is that even modest improvements in the operating efficiency of conventional technologies can have substantial environmental implications when that technology makes up a large share of the total market.

It is important to emphasize that operating efficiency is only one part in a broader set of considerations in evaluating the overall impact of electricity deregulation. Much of the economic literature has focused on how industry restructuring affects incentives for investment behavior, and entry/exit, as well as on the potential for centralized wholesale markets to increase efficiency. These considerations likely have significant consequences for welfare, particularly in the long-run. A related and perhaps even more important issue is the effect of restructuring on the risk of nuclear accidents. Our results provide mild evidence that one measure of reactor safety may have actually improved with divestiture, but this remains an important priority for future work. 


\section{$\underline{\text { References }}$}

Aigner, Dennis J. and Shih-Fan Chu. 1968. “On Estimating the Industry Production Function," American Economic Review, 58: 826-839.

Aigner, Dennis J., C.A. Knox Lovell, and Peter Schmidt. 1977. "Formulation and Estimation of Stochastic Frontier Production Function Models," Journal of Econometrics, 6: 21-37.

Altonji, Joseph G., Todd E. Elder and Christopher R. Taber. 2005. "Selection on Observed and Unobserved Variables: Assessing the Effectiveness of Catholic Schools," Journal of Political Economy, 113(1), 151-184.

Averch, Harvey and Leland L. Johnson. 1962. "Behavior of the Firm Under Regulatory Constraint," American Economic Review 52(5): 1052-1069.

Borenstein, Severin. 2008. "The Market Value and Cost of Solar Photovoltaic Electricity Projection," CSEM Working Paper \# 176.

Borenstein, Severin, James Bushnell, and Frank Wolak. 2002. "Measuring Market Inefficiencies in California's Restructured Wholesale Electricity Market," American Economic Review, 92(5): 1376-1405.

Bushnell, James, Erin Mansur and Celeste Saravia. 2008. "Vertical Arrangements, Market Structure, and Competition: An Analysis of Restructured U.S. Electricity Markets," American Economic Review, 98(1): 237-266.

Bushnell, James B. and Catherine Wolfram. 2005. "Ownership Change, Incentives and Plant Efficiency: The Divestiture of U.S. Electric Generation Plants," CSEM Working Paper Number 140.

Christensen, Lauritis R. and William H. Greene. 1976. "Economies of Scale in U.S. Electric Power Generation." Journal of Political Economy. 84(4): 655-76.

Craig, J. Dean and Scott J. Savage. 2011. "Market Restructuring, Competition and the Efficiency of Electric Generation: Plant-Level Evidence from the United States 1996 to 2006", University of Colorado Working Paper.

David, Paul A., Roland Maude-Griffin and Geoffrey Rothwell. 1996. "Learning by Accident? Reductions in the Risk of Unplanned Outages in U.S. Nuclear Power Plants After Three Mile Island." Journal of Risk and Uncertainty, 13: $175-198$.

Fabrizio, Kira R., Nancy L. Rose, and Catherine D. Wolfram. 2007. "Do Markets Reduce Costs? Assessing the Impact of Regulatory Restructuring on U.S. Electric Generation Efficiency." American Economic Review, 97(4), 1250-1277.

Focarelli, Dario and Fabio Panetta. 2003. "Are Mergers Beneficial to Consumers? Evidence from the Market for Bank Deposits.” American Economic Review, 93(4): 1152-1172.

Hausman, Catherine. 2011. “Corporate Incentives and Nuclear Safety.” UC Berkeley Working Paper, May 2011.

Hortacsu, Ali and Chad Syverson. 2007. "Cementing Relationships: Vertical Integration, Foreclosure, Productivity, and Prices." Journal of Political Economy, 115(2): 250-301.

Hortacsu, Ali and Steve Puller. 2008. "Understanding Strategic Bidding in Multi-Unit Auctions: A Case Study of the Texas Electricity Spot Market." RAND Journal of Economics, 39(1): 86-114.

Hortacsu, Ali, Seyed Ali Madanizadeh and Steve Puller. 2011. "Power to Choose: An Analysis of Consumer Behavior in the Texas Retail Electricity Market." Working paper.

Joskow, Paul L. 1973. "Pricing Decisions of Regulated Firms: A Behavioral Approach.” Bell Journal of Economics 4(1): 118-140

Joskow, Paul L. 1982. "Problems and Prospects for Nuclear Energy in the United States." in Energy, Economics, and the Environment, ed. Gregory A. Daneke, Lexington: D.C. Heath and Company.

Joskow, Paul L. 1997. "Restructuring, Competition and Regulatory Reform in the U.S. Electricity Sector." Journal of Economic Perspectives 11: 119-138.

Joskow, Paul L. 2005. “Regulation and Deregulation After 25 Years: Lessons Learned for Research in Industrial Organization.” Review of Industrial Organization 26 (2), 169-193.

Joskow, Paul L. 2011. "Comparing the Costs of Intermittent and Dispatchable Electricity Generating Technologies.” American Economic Review, 101(3): 238-241. 
Joskow, Paul L. and Edward Kahn. 2002. "A Quantitative Analysis of Pricing Behavior in California's Wholesale Electricity Market During Summer 2000.” Energy Journal 23(4), 1-35.

Joskow, Paul L. and John E. Parsons. 2009. “The Economic Future of Nuclear Power.” Daedalus, 138(4): 45-59.

Joskow, Paul L. and Nancy L. Rose. 1989. “The Effects of Economic Regulation.” In Handbook of Industrial Organization, North Holland.

Joskow, Paul L. and Nancy L. Rose. 1985. "The Effects of Technological Change, Experience, and Environmental Regulation on the Construction Cost of Coal-Burning Generating Units." RAND Journal of Economics 16(1), 1-17.

Joskow, Paul L. and George A. Rozanski. 1979. "The Effects of Learning by Doing on Nuclear Plant Operating Reliability." Review of Economics and Statistics, 61(2), 161-168.

Kleit, Andrew and Dek Terrell. 2001. "Alternative Regulatory Methods and Firm Efficiency: Stochastic Frontier Evidence from the U.S. Electricity Industry." Review of Economics and Statistics, 83(3), 523-530.

Knittel, Christopher R. 2002. "Alternative Regulatory Methods and Firm Efficiency: Stochastic Frontier Evidence from the U.S. Electricity Industry." Review of Economics and Statistics, 84(3), 530-540.

Mansur, Erin and Matthew White. 2010. “Market Organization and Efficiency in Electricity Markets.” Working paper.

Lester, Richard K. and Mark J. McCabe. 1993. "The Effect of Industrial Structure on Learning By Doing in Nuclear Power Plant Operation." RAND Journal of Economics, 24(3), 418-438.

Lyon, Thomas P. and John P. Mayo. 2005. "Regulatory Opportunism and Investment Behavior: Evidence from the Electric Utility Industry.” RAND Journal of Economics 37: 628-644.

Massachusetts Institute of Technology (MIT). 2003. "The Future of Nuclear Power: An Interdisciplinary MIT Study." MIT Energy Initiative.

Massachusetts Institute of Technology (MIT). 2009. "The Future of Nuclear Power: An Interdisciplinary MIT Study." MIT Energy Initiative.

Olley, G. Steven and Ariel Pakes. 1996. "The Dynamics of Productivity in the Telecommunications Equipment Industry." Econometrica, 64(6), 1263-1297.

Peltzman, Sam and Clifford Winston. 2000 Deregulation of Network Industries: What's Next? Washington, DC: Brookings Institution

Sappington, David E.M., Johannes P. Pfeifenberger, Philip Hanser, and Gregory N. Basheda. 2001. "The State of Performance-Based Regulation in the U.S. Electric Industry." Electricity Journal, 14(8), 71-79.

Shanefelter, Jennifer K. 2008. "Restructuring, Ownership and Efficiency: The Case of Labor in Electricity Generation." Department of Justice Working Paper, EAG 200812.

Syverson, Chad. 2004. "Market Structure and Productivity: A Concrete Example." Journal of Political Economy, 112(6), 1181-1222.

Syverson, Chad. 2011. "What Determines Productivity?” Journal of Economic Literature, 49(2), 326-365.

Verma, Kiran, Barry M. Mitnick, and Alfred A. Marcus. 1999. "Making Incentive Systems Work: Incentive Regulation in the Nuclear Power Industry." Journal of Public Administration Research and Theory, 9 (3), 395-436.

White, Matthew. 1996. "Power Struggles: Explaining Deregulatory Reforms in Electricity Markets.” Brookings Papers on Microeconomics, 201-267.

Winston, Clifford. 1993. "Economic Deregulation: Days of Reckoning for Microeconomists.” Journal of Economic Literature, 31(3): 1263-1289.

Wolfram, Catherine. 1999. "Measuring Duopoly Power in the British Electricity Spot Market." American Economic Review, 89(4): 805-826.

Wolfram, Catherine. 2004. "The Efficiency of Electricity Generation in the U.S. After Restructuring." in James Griffin and Steve Puller, eds., Electricity Deregulation: Choices and Challenges. University of Chicago Press: Chicago, IL.

Zhang, Fan. 2007. "Does Electricity Restructuring Work? Evidence From The U.S. Nuclear Energy Industry.” Journal of Industrial Economics, 55(3): 397-418. 
Figure 1: Net Generation Scaled By Reactor Design Capacity, 1970-2009

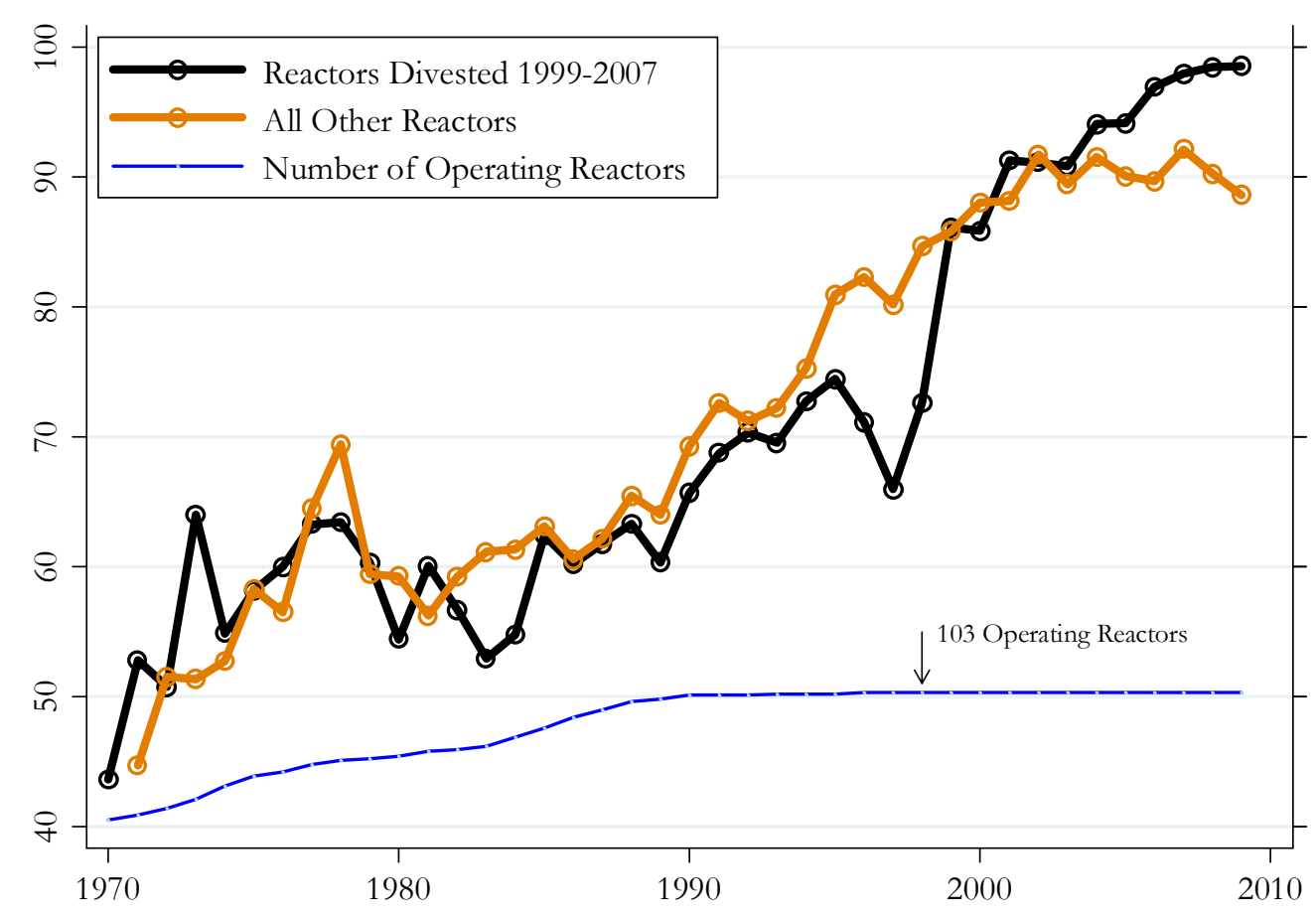

Figure 2: The Effect of Divestiture on Operating Efficiency by Month of Year

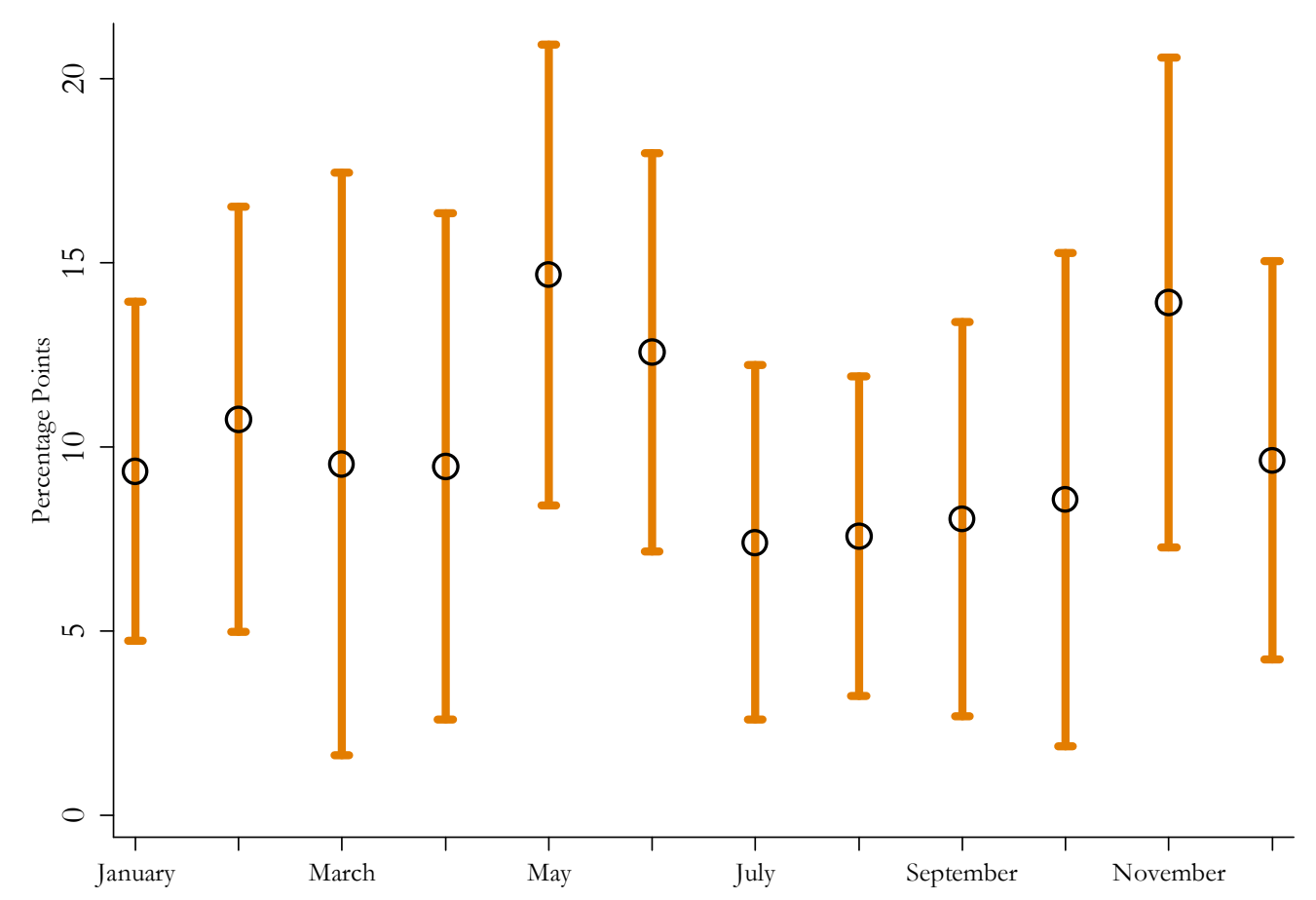


Figure 3: Number of Reactors Operated by the Same Operator, 1970-2009

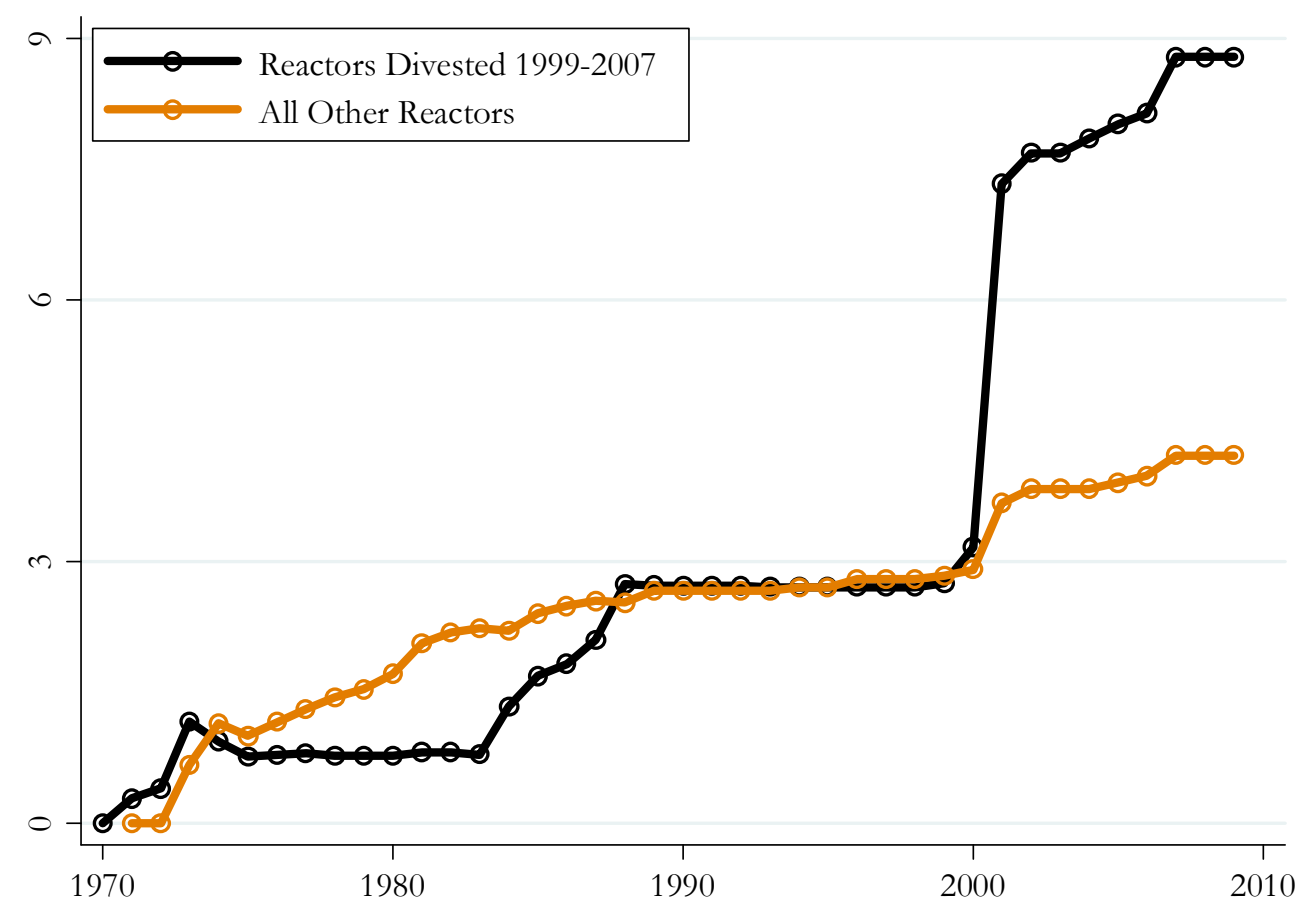

Figure 4: Licensed Thermal Capacity as a Percent of Original License, 1970-2009

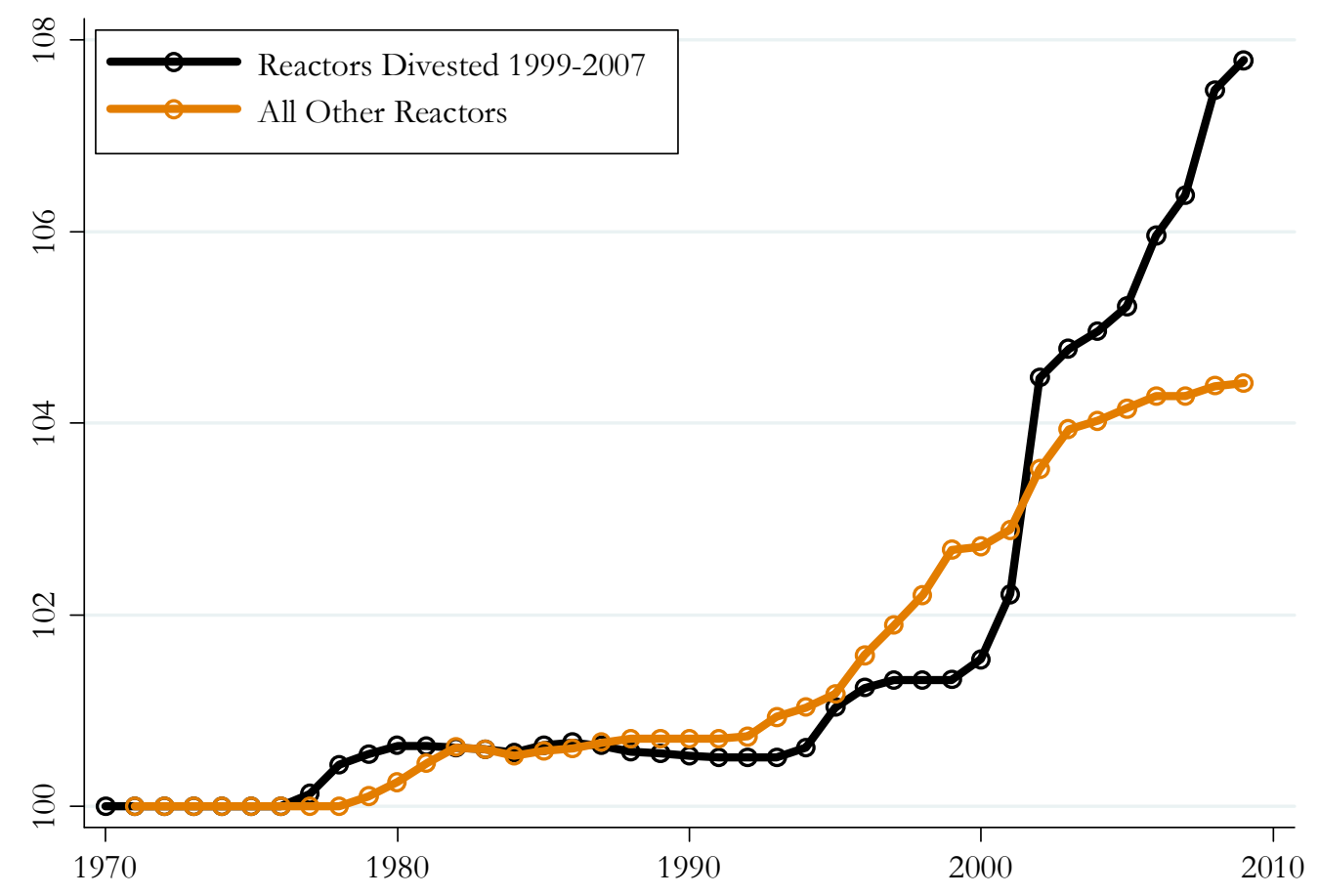


Figure 5: Fraction of Reactors Not Operating By Day, 1999-2009

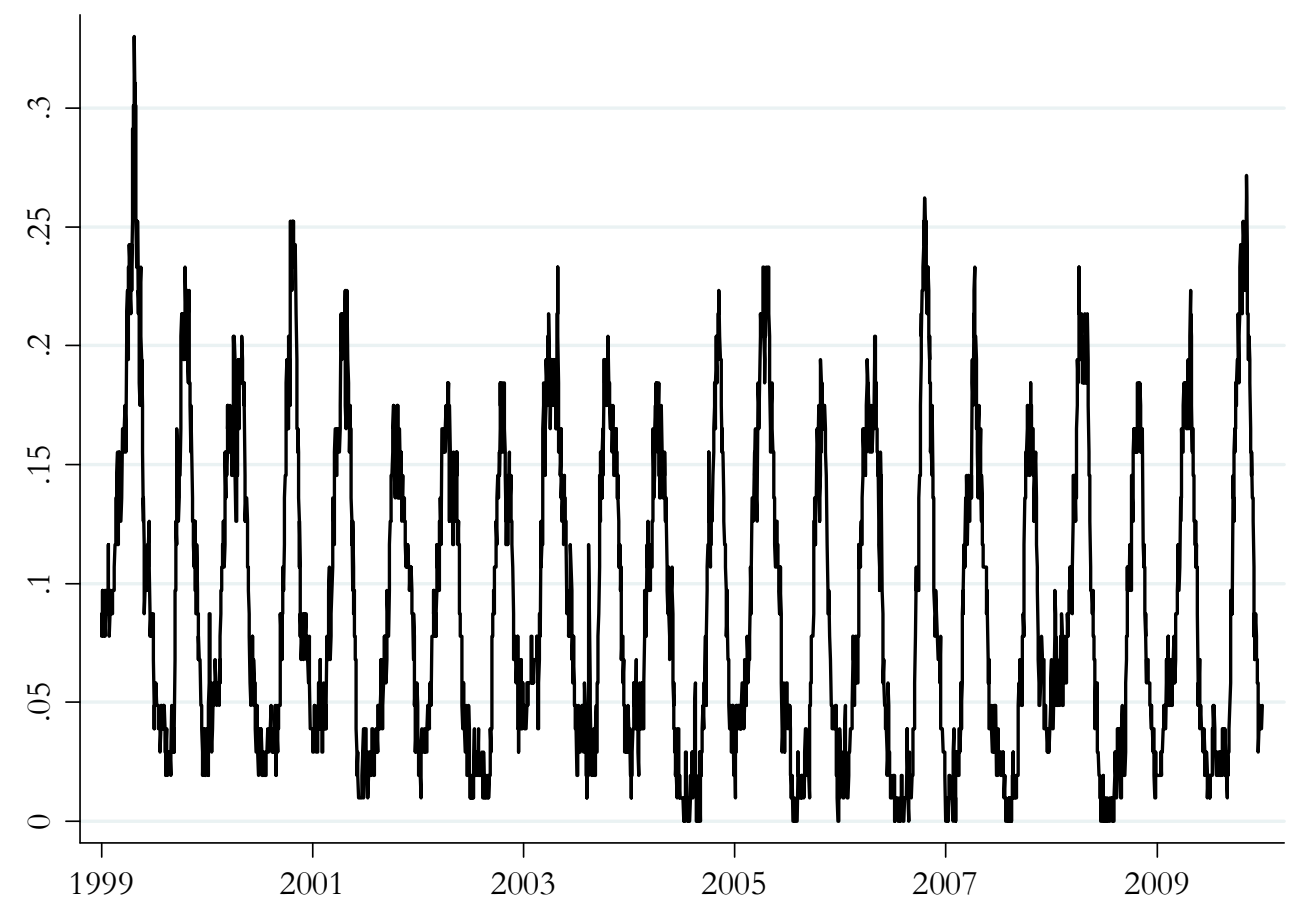

Figure 6: Fraction of Reactors Not Operating By Day of Year
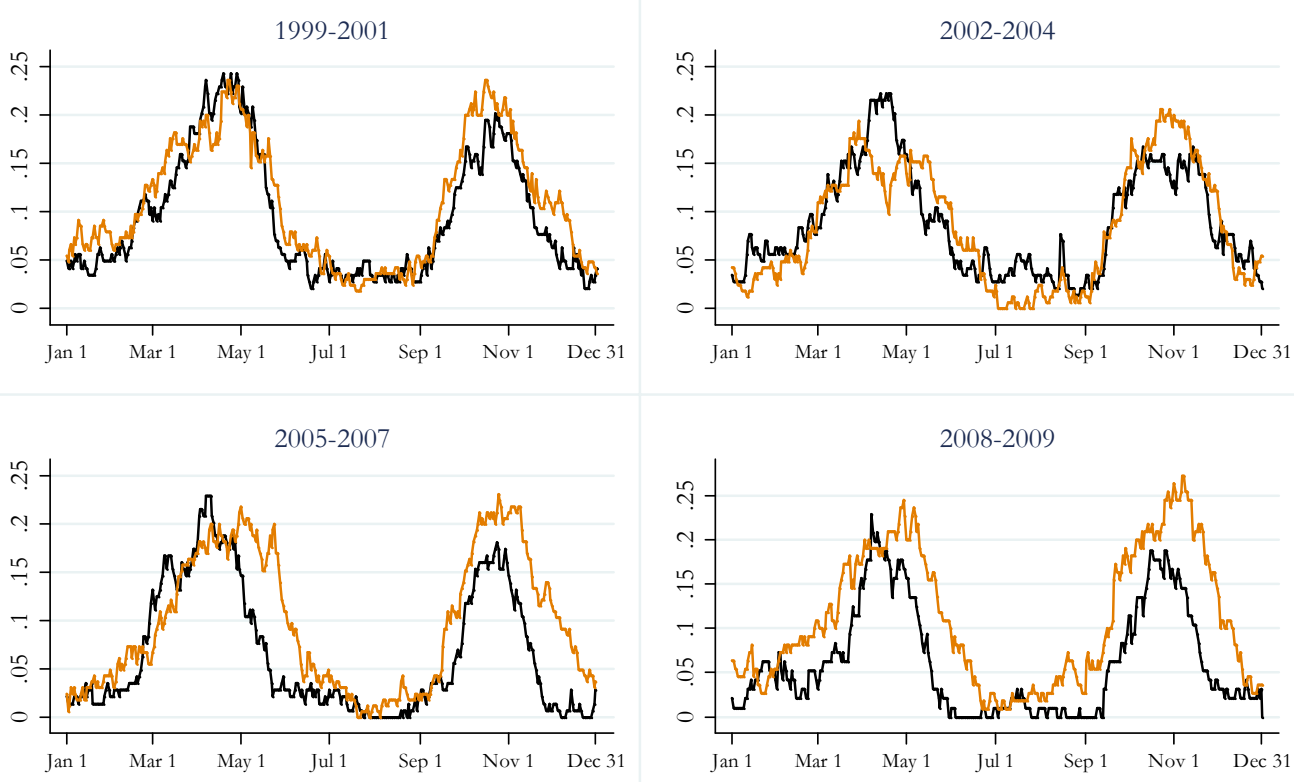

Reactors Divested 1999-2007 All Other Reactors 
Figure 7: Mean Number of Outage Days Per Year, 1999-2009

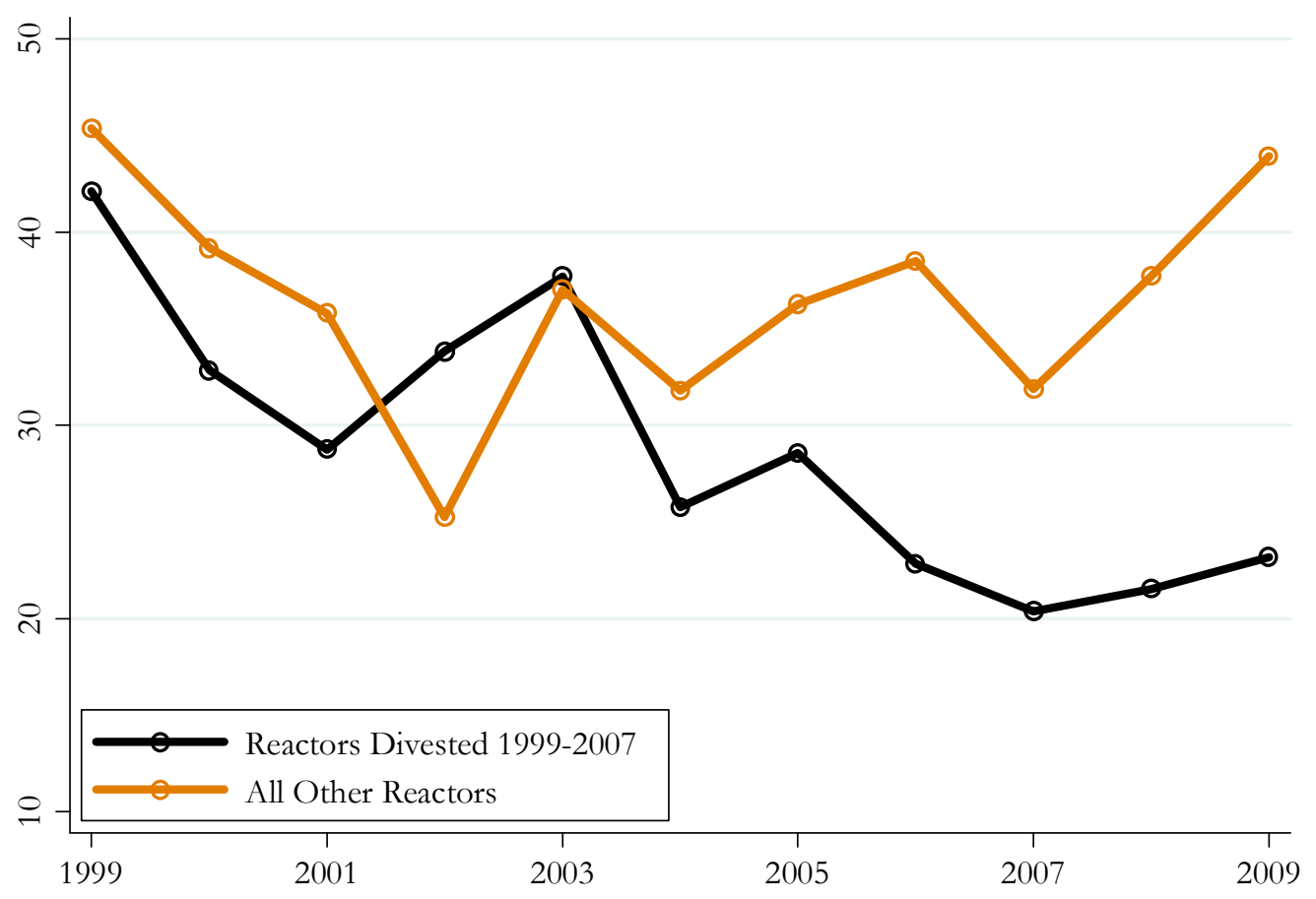

Figure 8: Mean Number of Scrams per Hour of Reactor Operation, 1999-2009

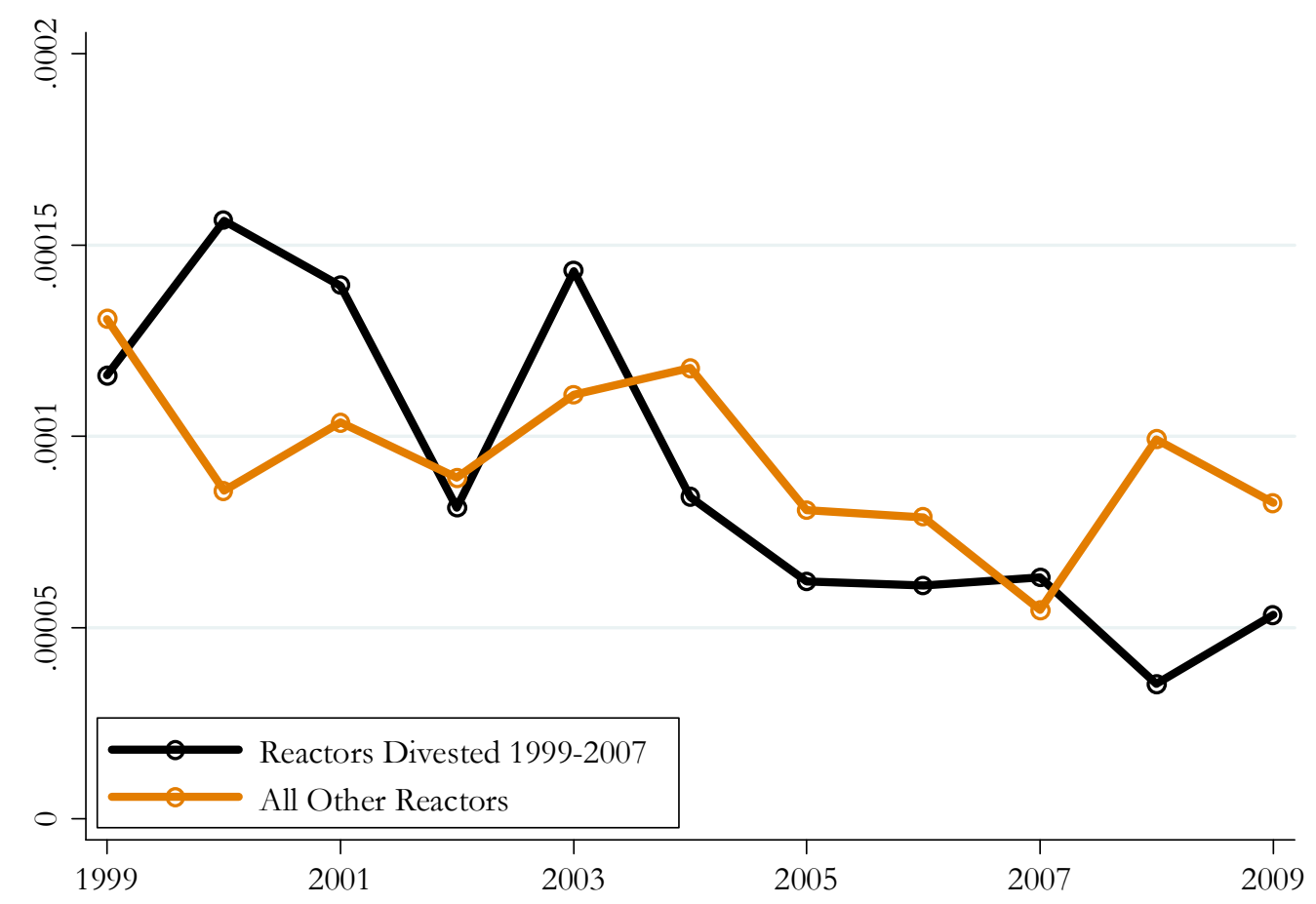


Figure 9: Mean Capacity Factor by Day of Year for Operating Reactors, 2005-2009

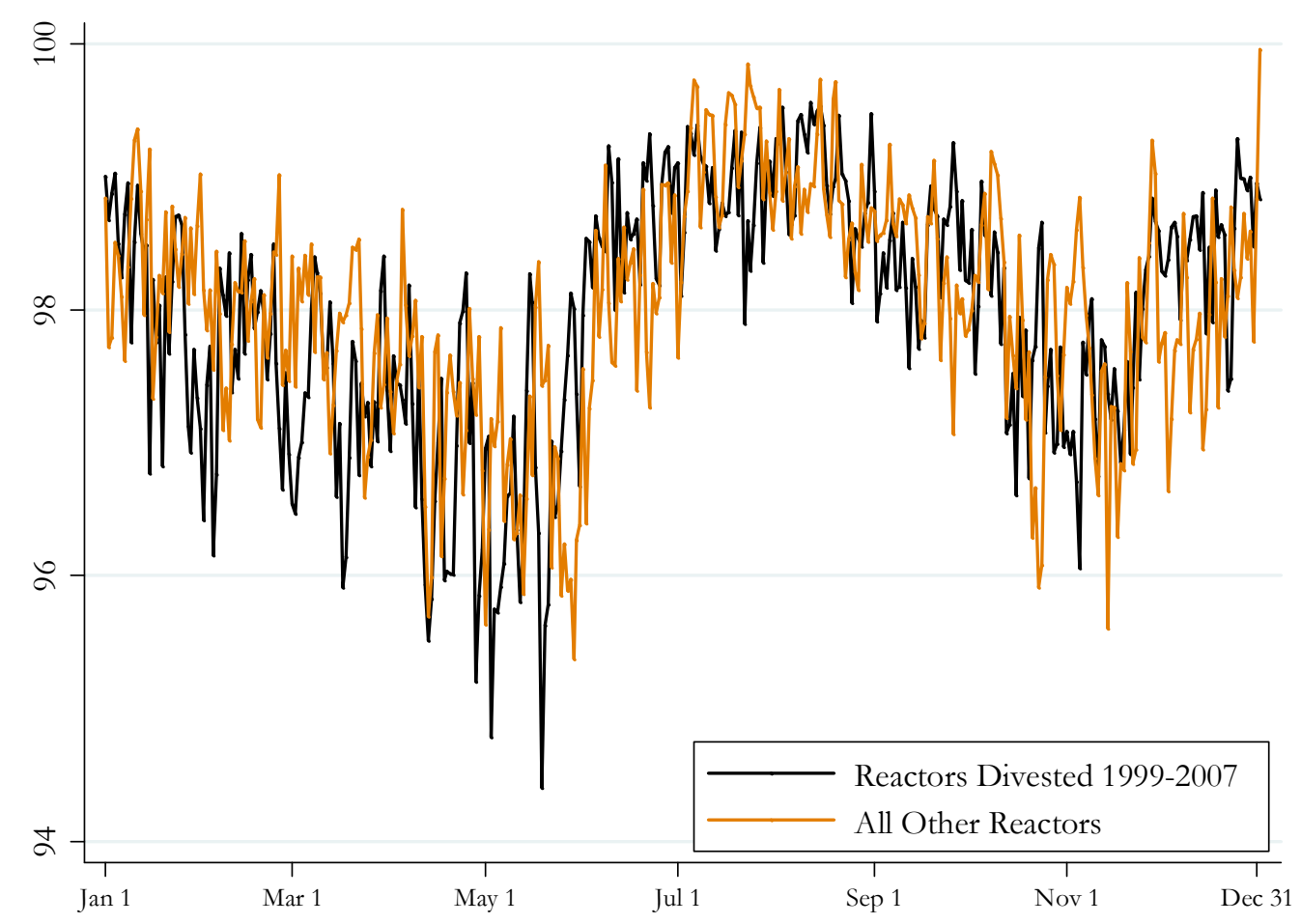


TABLE 1

Descriptive Statistics: U.S. Nuclear Power Reactors

A. Reactor Characteristics (103 total reactors)

Number of Reactors By Vintage

1960s

1970s

1980s

$1990 \mathrm{~s}$

Number of Reactors By Type

Pressurized Water Reactors

Boiling Water Reactors

Number of Reactors By Manufacturer

Westinghouse

General Electric

Combustion Engineering

Babcock and Wilcox

Notes: Our sample includes all reactors that were operating as of January 1, 2000. Vintage, reactor type, and reactor manufacturer come from the NRC Information Digest 20102011 (NUREG-1350, Volume 22), published August 2010. Vintage is defined as the decade the reactor began commercial operation. 
TABLE 1 (continued)

Descriptive Statistics: U.S. Nuclear Power Reactors

\section{B. Operating Efficiency and Reactor Outages}

Net Generation as a Percent of Design Capacity (Department of Energy)

$1970 \mathrm{~s}$

$61 \%$

$1980 \mathrm{~s}$

$61 \%$

$1990 \mathrm{~s}$

$75 \%$

2000s

$92 \%$

Daily Reactor Status 1999-2009 (Nuclear Regulatory Commission)

Percentage of Daily Observations at 100\% Capacity Factor $\quad 77 \%$

Percentage of Daily Observations at $90 \%$ - 99\% $\quad 9 \%$

Percentage of Daily Observations at 1\% - 89\% $\quad 4 \%$

Percentage of Daily Observations at 0\% $\quad 9 \%$

Outages 1999-2009 (Nuclear Regulatory Commission)

Percentage of Outage Days Manual Shutdown for Refueling $\quad 73 \%$

Percentage of Outage Days Manual Shutdown for Other Reasons $\quad 24 \%$

Percentage of Outage Days Automatic Shutdown ("scram") 2\%

Notes: This table describes operating efficiency and reactor outages for the 103 U.S. nuclear power reactors that were operating in the United States as of January 1, 2000. Capacity factor in the first four rows was calculated by the authors by dividing generation levels from U.S. Department of Energy, Energy Information Administration, Power Plant Report (EIA-906), 1970-2009 by design capacity (in MWe) from U.S. Department of Energy, Energy Information Administration, Nuclear Power Generation and Fuel Cycle Report 1997, “Appendix C: Nuclear Units Ordered in the United States, 1953-1996." Daily reactor status and explanations for outages come from U.S. NRC, Power Status Reports. 
TABLE 2

Comparing Divested With Non-Divested Nuclear Reactors

(1)

$\begin{array}{ccc}\text { Reactors } & \text { All Other } & p \text {-value } \\ \text { Divested } & \text { Reactors } & (1) \text { vs (2) } \\ \begin{array}{c}1999-2007 \\ (\mathrm{n}=48)\end{array} & (\mathrm{n}=55) & \\ & & \end{array}$

Reactor Characteristics

Mean Design Capacity (in MWe)

Mean Reactor Age as of December 1998

Number of Reactors Operated by the Same Reactor

Operator as of December 1998

Original Construction Cost Per Kilowatt Capacity

(in Year 2010 dollars)

Reactor Type

Percentage Pressurized Water Reactor

Percentage Boiling Water Reactor

Reactor Manufacturer

Percentage Westinghouse

Percentage General Electric

Percentage Combustion Engineering

Percentage Babcock and Wilcox

Reactor Location

Percentage Northeast Census Region

Percentage Midwest Census Region

Percentage South Census Region

Percentage West Census Region
921.9

959.7

.38

18.8

18.4

.74

2.7

2.8

.86

$\$ 2,397$

$\$ 2,298$

.81

$\begin{array}{lll}54 \% & 78 \% & .01 \\ 46 \% & 22 \% & .01\end{array}$

$\begin{array}{ccc}42 \% & 51 \% & .35 \\ 46 \% & 22 \% & .01 \\ 8 \% & 18 \% & .15 \\ 4 \% & 9 \% & .33\end{array}$

$\begin{array}{ccc}50 \% & 0 \% & .00 \\ 38 \% & 18 \% & .03 \\ 13 \% & 67 \% & .00 \\ 0 \% & 15 \% & .01\end{array}$

Notes: The sample includes all 103 nuclear power reactors operating in the United States as of January 1, 2000. Year the reactor began commercial operation, reactor type, reactor manufacturer, and reactor location come from the $N R C$ Information Digest 2010-2011 (NUREG-1350, Volume 22), published August 2010. Original construction cost per kilowatt was calculated by the authors using data from FERC, Form 1 for 1996. Column (3) reports $p$-values from tests that the means are equal in the two subsamples. 
TABLE 3

The Effect of Divestiture on Nuclear Operating Efficiency

\begin{tabular}{|c|c|c|c|c|c|}
\hline & (1) & $(2)$ & (3) & $(4)$ & (5) \\
\hline \multirow{2}{*}{$1[\text { Divested }]_{\mathrm{it}}$} & $6.5^{* *}$ & $10.4^{* *}$ & $10.2^{* *}$ & $10.2^{* *}$ & $9.7^{* *}$ \\
\hline & $(1.2)$ & $(2.1)$ & $(2.0)$ & $(2.0)$ & $(2.0)$ \\
\hline Month-of-Sample Fixed Effects (480 months) & Yes & Yes & Yes & Yes & Yes \\
\hline Reactor Fixed Effects (103 reactors) & No & Yes & Yes & Yes & Yes \\
\hline Reactor Age (cubic) & No & No & Yes & Yes & Yes \\
\hline Observations Weighted By Reactor Capacity & No & No & No & Yes & No \\
\hline Dataset Collapsed To Plant Level & No & No & No & No & Yes \\
\hline Number of Cross Sectional Units & 103 & 103 & 103 & 103 & 65 \\
\hline Number of Observations & 36,667 & 36,667 & 36,667 & 36,667 & 23,796 \\
\hline $\mathrm{R}^{2}$ & .18 & .22 & .22 & .22 & .26 \\
\hline \multicolumn{6}{|c|}{$\begin{array}{l}\text { Notes: This table reports coefficient estimates and standard errors corresponding to an indicator variable for reactors that } \\
\text { have been divested from five separate regressions. In all regressions the dependent variable is net generation as a percent } \\
\text { of design capacity. The sample includes monthly observations 1970-2009 for all } 103 \text { nuclear power reactors operating in } \\
\text { the United States as of January } 1,2000 \text {. Standard errors are clustered at the plant level. Single and double asterisks denote } \\
\text { statistical significance at the } 5 \% \text { and } 1 \% \text { level. }\end{array}$} \\
\hline
\end{tabular}


TABLE 4

The Effect of Divestiture By Reactor Design, Manufacturer, Vintage, and Type of Sale

\begin{tabular}{|c|c|c|c|c|}
\hline & $\begin{array}{c}(1) \\
\text { By Reactor } \\
\text { Design } \\
\end{array}$ & $\begin{array}{c}\text { (2) } \\
\text { By Reactor } \\
\text { Manufacturer }\end{array}$ & $\begin{array}{c}\text { (3) } \\
\text { By Reactor } \\
\text { Vintage }\end{array}$ & $\begin{array}{c}(4) \\
\text { By Type of Sale }\end{array}$ \\
\hline Pressurized Water Reactors $(n=22)$ & $\begin{array}{l}9.5^{* *} \\
(2.5)\end{array}$ & & & \\
\hline Boiling Water Reactors $(n=26)$ & $\begin{array}{c}10.8^{* *} \\
(2.7)\end{array}$ & & & \\
\hline Westinghouse $(n=20)$ & & $\begin{array}{l}10.0^{* *} \\
(2.9)\end{array}$ & & \\
\hline General Electric $(n=22)$ & & $\begin{array}{c}10.8^{* *} \\
(2.7)\end{array}$ & & \\
\hline Combustion Engineering $(n=4)$ & & $\begin{array}{c}5.9 \\
(3.4)\end{array}$ & & \\
\hline Babcock and Wilcox $(n=2)$ & & $\begin{array}{c}12.5^{* *} \\
(1.9)\end{array}$ & & \\
\hline Completed Before $1975(n=17)$ & & & $\begin{array}{c}10.3^{* *} \\
(2.7)\end{array}$ & \\
\hline Completed $1975-1985(n=13)$ & & & $\begin{array}{c}13.7^{* *} \\
(3.6)\end{array}$ & \\
\hline Completed After $1985(\mathrm{n}=18)$ & & & $\begin{array}{l}7.2^{* *} \\
(2.6)\end{array}$ & \\
\hline External Sales $(n=19)$ & & & & $\begin{array}{c}11.5^{* *} \\
(2.8)\end{array}$ \\
\hline Internal Sales $(n=29)$ & & & & $\begin{array}{l}9.4^{* *} \\
(2.3)\end{array}$ \\
\hline Month-of-Sample Fixed Effects (480 months) & Yes & Yes & Yes & Yes \\
\hline Reactor Fixed Effects (103 reactors) & Yes & Yes & Yes & Yes \\
\hline Reactor Age (cubic) & Yes & Yes & Yes & Yes \\
\hline Number of Observations & 36,667 & 36,667 & 36,667 & 36,667 \\
\hline $\mathrm{R}^{2}$ & .22 & .22 & .22 & .22 \\
\hline $\begin{array}{l}\text { Notes: This table reports coefficient estima } \\
\text { dependent variable is net generation as a } \\
\text { between the variables indicated in the row } \\
\text { sample includes monthly observations } 1970 \\
\text { January } 1,2000 \text {. Standard errors are cluster } \\
\text { at the } 5 \% \text { and } 1 \% \text { level. In none of the fo } \\
\text { coefficients are equal. The } n \text {-values from the }\end{array}$ & $\begin{array}{l}\text { standard er } \\
t \text { of design } \\
\text { gs and an in } \\
\text { for all } 103 \mathrm{r} \\
\text { e plant leve } \\
\text { essions is it } \\
\text { f equal coeff }\end{array}$ & $\begin{array}{l}\text { rom four separ } \\
\text { ty. Coefficients } \\
\text { or variable for } r \\
r \text { power reactor } \\
\text { le and double as } \\
\text { ible to reject th } \\
\text { are } 68.1231\end{array}$ & $\begin{array}{l}\text { gressions. In } \\
\text { eported fron } \\
\text { rs that have } \\
\text { rating in the } \\
\text { ks denote st: } \\
1 \text { hypothesis } \\
51 \text { respecti }\end{array}$ & $\begin{array}{l}\text { regressions the } \\
\text { teraction terms } \\
\text { en divested. The } \\
\text { ited States as of } \\
\text { ical significance } \\
\text { the estimated }\end{array}$ \\
\hline
\end{tabular}


TABLE 5

The Effect of Divestiture and Consolidation on Nuclear Operating Efficiency

\begin{tabular}{|c|c|c|c|c|c|c|}
\hline & $\begin{array}{c}(1) \\
\text { Reactor- } \\
\text { Level }\end{array}$ & $\begin{array}{c}(2) \\
\text { Reactor- } \\
\text { Level }\end{array}$ & $\begin{array}{c}\text { (3) } \\
\text { Reactor- } \\
\text { Level }\end{array}$ & $\begin{array}{c}(4) \\
\text { Reactor- } \\
\text { Level }\end{array}$ & $\begin{array}{c}(5) \\
\text { Reactor- } \\
\text { Level }\end{array}$ & $\begin{array}{c}\text { (6) } \\
\text { Plant- } \\
\text { Level } \\
\end{array}$ \\
\hline $1[\text { Divested }]_{\text {it }}$ & $\begin{array}{c}10.2^{* *} \\
(2.0)\end{array}$ & $\begin{array}{l}7.8^{* *} \\
(2.3)\end{array}$ & $\begin{array}{l}8.4^{* *} \\
(1.9)\end{array}$ & $\begin{array}{l}8.7^{* *} \\
(2.1)\end{array}$ & $\begin{array}{l}\text { Excluding } \\
\text { Divested } \\
\text { Reactors }\end{array}$ & $\begin{array}{l}6.5^{* *} \\
(2.1)\end{array}$ \\
\hline $\begin{array}{l}\text { Number of Reactors/Plants Operated by the } \\
\text { Same Operator }\end{array}$ & -- & $\begin{array}{l}.48 \\
(.28)\end{array}$ & -- & -- & $\begin{array}{l}.87^{*} \\
(.34)\end{array}$ & $\begin{array}{l}.98^{*} \\
(.38)\end{array}$ \\
\hline $\begin{array}{l}\text { Number of Same-Type Reactors (PWR/BWR) } \\
\text { Operated by the Same Operator }\end{array}$ & -- & -- & $\begin{array}{c}.64 \\
(.44)\end{array}$ & -- & -- & -- \\
\hline $\begin{array}{l}\text { Number of Same-Manufacturer Reactors } \\
\text { Operated by the Same Operator }\end{array}$ & -- & -- & -- & $\begin{array}{l}.61 \\
(.43)\end{array}$ & -- & -- \\
\hline Month-of-Sample Fixed Effects (480 months) & Yes & Yes & Yes & Yes & Yes & Yes \\
\hline Reactor/Plant Fixed Effects (103 reactors) & Yes & Yes & Yes & Yes & Yes & Yes \\
\hline Reactor/Plant Age (cubic) & Yes & Yes & Yes & Yes & Yes & Yes \\
\hline Mean of Consolidation Variable & - & 3.3 & 2.1 & 1.7 & 2.9 & 1.5 \\
\hline Number of Observations & 36,667 & 36,667 & 36,667 & 36,667 & 19,446 & 23,796 \\
\hline $\mathrm{R}^{2}$ & .22 & .22 & .22 & .22 & .21 & .27 \\
\hline
\end{tabular}


TABLE 6

Considering Possible Concerns About Selection Bias, Long Outages, and Closures

\begin{tabular}{|c|c|c|c|c|c|c|c|c|c|c|c|}
\hline & \multicolumn{6}{|c|}{ Selection Bias } & \multicolumn{4}{|c|}{ Long Outages 1996-1998 } & \multirow{2}{*}{$\begin{array}{c}\text { Closures } \\
\\
(11) \\
\text { Including } \\
\text { Five Closed } \\
\text { Reactors } \\
\text { with } \\
\text { Imputed } \\
\text { Post-Close } \\
\text { Operations }\end{array}$} \\
\hline & $\begin{array}{l}\text { (1) } \\
\text { Excluding } \\
\text { Michigan }\end{array}$ & $\begin{array}{l}\quad(2) \\
\text { Excluding } \\
\text { California }\end{array}$ & $\begin{array}{c}\text { (3) } \\
\text { Excluding } \\
\text { Iowa and } \\
\text { Wisconsin }\end{array}$ & $\begin{array}{c}\text { (4) } \\
\text { Divest } \\
\text { Date } \\
1 / 1 / 2001 \\
\text { For All } \\
\text { Reactors }\end{array}$ & $\begin{array}{l}(5) \\
\text { Excluding } \\
\text { the } \\
\text { Northeast } \\
\text { Census } \\
\text { Region }\end{array}$ & $\begin{array}{c}(6) \\
\text { Propensity } \\
\text { Score } \\
\text { Weighting }\end{array}$ & $\begin{array}{c}(7) \\
\text { Excluding } \\
\text { Years } \\
1996- \\
1998\end{array}$ & $\begin{array}{c}\text { (8) } \\
\text { Excluding } \\
\text { 12+ Month } \\
\text { Outages } \\
\text { 1996-1998 }\end{array}$ & $\begin{array}{c}(9) \\
\text { Excluding } \\
\text { Reactors } \\
\text { With 12+ } \\
\text { Month } \\
\text { Outages } \\
\text { 1996-1998 }\end{array}$ & $\begin{array}{c}(10) \\
\text { Including } \\
\text { Indicator } \\
\text { Variables } \\
\text { for All 12+ } \\
\text { Month } \\
\text { Outages, } \\
\text { During and } \\
\text { After } \\
\end{array}$ & \\
\hline $1[\text { Divested }]_{\text {it }}$ & $\begin{array}{l}9.7^{* *} \\
(2.0)\end{array}$ & $\begin{array}{c}10.4^{* *} \\
(2.1)\end{array}$ & $\begin{array}{l}10.3^{* *} \\
(2.1)\end{array}$ & $\begin{array}{l}7.9^{* *} \\
(2.4)\end{array}$ & $\begin{array}{l}10.0^{* *} \\
(2.6)\end{array}$ & $\begin{array}{l}11.0^{* *} \\
(3.1)\end{array}$ & $\begin{array}{l}8.8^{* *} \\
(2.0)\end{array}$ & $\begin{array}{l}9.1^{* *} \\
(2.1)\end{array}$ & $\begin{array}{l}8.2^{* *} \\
(1.9)\end{array}$ & $\begin{array}{l}7.4^{* *} \\
(1.5)\end{array}$ & $\begin{array}{l}8.6^{* *} \\
(1.7)\end{array}$ \\
\hline $\begin{array}{l}\text { Month-of-Sample } \\
\text { Fixed Effects } \\
\text { Reactor Fixed Effects }\end{array}$ & $\begin{array}{l}\text { Yes } \\
\text { Yes }\end{array}$ & $\begin{array}{l}\text { Yes } \\
\text { Yes }\end{array}$ & $\begin{array}{l}\text { Yes } \\
\text { Yes }\end{array}$ & $\begin{array}{l}\text { Yes } \\
\text { Yes }\end{array}$ & $\begin{array}{l}\text { Yes } \\
\text { Yes }\end{array}$ & $\begin{array}{l}\text { Yes } \\
\text { Yes }\end{array}$ & $\begin{array}{l}\text { Yes } \\
\text { Yes }\end{array}$ & $\begin{array}{l}\text { Yes } \\
\text { Yes }\end{array}$ & $\begin{array}{l}\text { Yes } \\
\text { Yes }\end{array}$ & $\begin{array}{l}\text { Yes } \\
\text { Yes }\end{array}$ & $\begin{array}{l}\text { Yes } \\
\text { Yes }\end{array}$ \\
\hline Reactor Age (cubic) & Yes & Yes & Yes & Yes & Yes & Yes & Yes & Yes & Yes & Yes & Yes \\
\hline Number of Reactors & 99 & 99 & 99 & 103 & 79 & 71 & 103 & 103 & 93 & 103 & 108 \\
\hline $\begin{array}{l}\text { Number of } \\
\text { Observations }\end{array}$ & 35,459 & 35,155 & 34,905 & 36,667 & 27,825 & 25,484 & 32,963 & 36,452 & 33,177 & 36,667 & 38,705 \\
\hline $\mathrm{R}^{2}$ & .23 & .22 & .23 & .22 & .21 & .22 & .24 & .22 & .23 & .34 & .22 \\
\hline
\end{tabular}


TABLE 7

Understanding the Mechanisms behind Post-Divestiture Gains

(1)

(2)

(3)

A. Maximum Generating Capacity

$\begin{array}{lccc}\text { Maximum Generation Over Last } 12 \text { Operating Months } & 2.5^{* *} & 1.6 & 1.7 \\ \text { [Sample Mean: 100.4] } & (0.9) & (1.5) & (1.4) \\ \text { Maximum Licensed Thermal Capacity }\left(\mathrm{MW}_{\mathrm{t}}\right) & 1.9 & 2.0 & 1.9 \\ \text { [Sample Mean: } 102.0] & (1.1) & (1.1) & (1.1)\end{array}$

B1. Operating Days and Shutdowns

$1[\text { Operating }]_{\text {it }} \mathrm{x} 100$

[Sample Mean: 91.0]

$1[$ Scram $]$ it x 100

[Sample Mean: 0.2]
$3.9^{* *}$

(0.7)

$-.01$

(.02)
3.5

(2.0)

$-.06$

(.04)
3.8*

$-.06$

(.04)

B2. Length Versus Number of Outages

Number of Outages per Year

[Sample Mean: 1.7]

Mean Outage Length in Days

[Sample Mean: 19.1]
$-.17$

(.11)

$-6.4^{* *}$

(1.3)
$-.13$

(.16)

$-6.2$

(5.4)
$-.13$

C. Capacity Factor when Operating

Capacity Factor in Percent Excluding Zeros

[Sample Mean: 97.7]
$-0.3$

$(0.3)$
0.5

$(0.3)$
0.4

\begin{tabular}{llll}
\hline Time Effects (4,017 days / 11 years) & Yes & Yes & Yes \\
Reactor Fixed Effects (103 reactors) & No & Yes & Yes \\
Reactor Age (cubic) & No & No & Yes \\
\hline
\end{tabular}

Notes: This table reports coefficient estimates and standard errors corresponding to an indicator variable for reactors that have been divested from 24 separate regressions. The row headings list the dependent variable used in each regression. The sample in all regressions includes the 103 nuclear power reactors operating in the United States as of January 1, 2000. The regressions described in the first two rows are estimated using monthly data. All other regressions are estimated using the daily data from the NRC. Both measures of maximum generating capacity are expressed as a percent of the original design capacity. Standard errors are clustered at the plant level. Single and double asterisks denote statistical significance at the $5 \%$ and $1 \%$ level. 
APPENDIX TABLE 1

U.S. Nuclear Reactors Divestitures (1999-2007)

\begin{tabular}{|c|c|c|c|c|c|}
\hline Reactor Name & $\begin{array}{c}\text { Design } \\
\text { Capacity }\end{array}$ & State & Sales Date & Seller & Buyer \\
\hline Pilgrim & 655 & MA & 7/1999 & Boston Edison Co & Entergy \\
\hline Clinton & 950 & IL & 12/1999 & Illinois Power Co & Amergen (Exelon) \\
\hline Three Mile Island 1 & 819 & PA & $12 / 1999$ & GPU Nuclear Corp & Amergen (Exelon) \\
\hline Calvert Cliffs 1 & 845 & MD & $7 / 2000$ & Baltimore Gas \& Electric & Constellation \\
\hline Calvert Cliffs 2 & 845 & MD & $7 / 2000$ & Baltimore Gas \& Electric & Constellation \\
\hline Susquehanna 1 & 1065 & PA & $7 / 2000$ & Penn Power and Light & PPL Corp \\
\hline Susquehanna 2 & 1052 & PA & $7 / 2000$ & Penn Power and Light & PPL Corp \\
\hline Hope Creek 1 & 1067 & NJ & $8 / 2000$ & Public Service E\&G & PSEG Power \\
\hline Oyster Creek & 650 & NJ & $8 / 2000$ & GPU Nuclear Corp & Amergen (Exelon) \\
\hline Salem 1 & 1090 & NJ & $8 / 2000$ & Public Service E\&G & PSEG Power \\
\hline Salem 2 & 1115 & NJ & $8 / 2000$ & Public Service E\&G & PSEG Power \\
\hline Fitzpatrick & 821 & NY & $11 / 2000$ & Power Authority of New York & Entergy \\
\hline Indian Point 3 & 965 & NY & $11 / 2000$ & Power Authority of New York & Entergy \\
\hline Braidwood 1 & 1120 & IL & $1 / 2001$ & Commonwealth Edison & Exelon \\
\hline Braidwood 2 & 1120 & IL & $1 / 2001$ & Commonwealth Edison & Exelon \\
\hline Byron 1 & 1120 & IL & $1 / 2001$ & Commonwealth Edison & Exelon \\
\hline Byron 2 & 1120 & IL & $1 / 2001$ & Commonwealth Edison & Exelon \\
\hline Dresden 2 & 794 & IL & $1 / 2001$ & Commonwealth Edison & Exelon \\
\hline Dresden 3 & 794 & IL & $1 / 2001$ & Commonwealth Edison & Exelon \\
\hline La Salle 1 & 1078 & IL & $1 / 2001$ & Commonwealth Edison & Exelon \\
\hline La Salle 2 & 1078 & IL & $1 / 2001$ & Commonwealth Edison & Exelon \\
\hline Limerick 1 & 1065 & $\mathrm{PA}$ & $1 / 2001$ & Philadelphia Electric Co & Exelon \\
\hline Limerick 2 & 1065 & PA & $1 / 2001$ & Philadelphia Electric Co & Exelon \\
\hline Peach Bottom 2 & 1065 & PA & $1 / 2001$ & Philadelphia Electric Co & Exelon \\
\hline Peach Bottom 3 & 1065 & PA & $1 / 2001$ & Philadelphia Electric Co & Exelon \\
\hline Quad Cities 1 & 789 & IL & $1 / 2001$ & Commonwealth Edison & Exelon \\
\hline Quad Cities 2 & 789 & IL & $1 / 2001$ & Commonwealth Edison & Exelon \\
\hline Millstone 2 & 870 & $\mathrm{CT}$ & $3 / 2001$ & Northeast Nuclear & Dominion \\
\hline Millstone 3 & 1156 & $\mathrm{CT}$ & $3 / 2001$ & Northeast Nuclear & Dominion \\
\hline Indian Point 2 & 873 & NY & $9 / 2001$ & Consolidated Edison Co of NY & Entergy \\
\hline Nine Mile Point 1 & 620 & NY & $11 / 2001$ & Niagara Mohawk Power & Constellation \\
\hline Nine Mile Point 2 & 1080 & NY & $11 / 2001$ & Niagara Mohawk Power & Constellation \\
\hline
\end{tabular}


APPENDIX TABLE 1 (continued)

U.S. Nuclear Reactors Divestitures 1999-2007

\begin{tabular}{|c|c|c|c|c|c|}
\hline Reactor Name & $\begin{array}{l}\text { Design } \\
\text { Capacity } \\
\end{array}$ & State & Sales Date & Seller & Buyer \\
\hline Comanche Peak 1 & 1150 & $\mathrm{TX}$ & $1 / 2002$ & Texas Utilities Electric Co & TXU Generation \\
\hline Comanche Peak 2 & 1150 & $\mathrm{TX}$ & $1 / 2002$ & Texas Utilities Electric Co & TXU Generation \\
\hline Vermont Yankee & 514 & VT & $7 / 2002$ & $\begin{array}{l}\text { Vermont Yankee Nuclear } \\
\text { Power Corporation }\end{array}$ & Entergy \\
\hline Seabrook 1 & 1198 & $\mathrm{NH}$ & $11 / 2002$ & $\begin{array}{l}\text { North Atlantic Energy } \\
\text { Services Corporation }\end{array}$ & FPL Group \\
\hline South Texas 1 & 1250 & $\mathrm{TX}$ & $1 / 2003$ & Reliant & CenterPoint \\
\hline South Texas 2 & 1250 & $\mathrm{TX}$ & $1 / 2003$ & Reliant & CenterPoint \\
\hline Ginna & 470 & NY & $6 / 2004$ & Rochester Gas \& Electric & Constellation \\
\hline Kewaunee & 535 & WI & $7 / 2005$ & Wisconsin Public Service & Dominion \\
\hline Beaver Valley 1 & 835 & PA & $12 / 2005$ & $\begin{array}{l}\text { Pennsylvania Power } \\
\text { Company }\end{array}$ & FirstEnergy \\
\hline Beaver Valley 2 & 852 & PA & $12 / 2005$ & $\begin{array}{l}\text { Pennsylvania Power } \\
\text { Company }\end{array}$ & FirstEnergy \\
\hline Davis-Besse & 906 & $\mathrm{OH}$ & $12 / 2005$ & Toledo Edison Co & FirstEnergy \\
\hline Perry 1 & 1205 & $\mathrm{OH}$ & $12 / 2005$ & Cleveland Electric & FirstEnergy \\
\hline Duane Arnold & 538 & IA & $1 / 2006$ & Interstate Power And Light & FPL Group \\
\hline Palisades & 805 & MI & $4 / 2007$ & Consumers Energy Co & Entergy \\
\hline Point Beach 1 & 497 & WI & $10 / 2007$ & Wisconsin Electric Power & FPL Group \\
\hline Point Beach 2 & 497 & WI & $10 / 2007$ & Wisconsin Electric Power & FPL Group \\
\hline
\end{tabular}

